\title{
Active Thermitic Material Discovered in Dust from the 9/11 World Trade Center Catastrophe
}

\author{
Niels H. Harrit ${ }^{*}{ }^{1}$, Jeffrey Farrer ${ }^{2}$, Steven E. Jones ${ }^{*}{ }^{3}$, Kevin R. Ryan ${ }^{4}$, Frank M. Legge ${ }^{5}$, \\ Daniel Farnsworth ${ }^{2}$, Gregg Roberts ${ }^{6}$, James R. Gourley ${ }^{7}$ and Bradley R. Larsen ${ }^{3}$
}

\author{
${ }^{I}$ Department of Chemistry, University of Copenhagen, Denmark \\ ${ }^{2}$ Department of Physics and Astronomy, Brigham Young University, Provo, UT 84602, USA \\ ${ }^{3} S \& J$ Scientific Co., Provo, UT, 84606, USA \\ ${ }^{4}$ 9/11 Working Group of Bloomington, Bloomington, IN 47401, USA \\ ${ }^{5}$ Logical Systems Consulting, Perth, Western Australia \\ ${ }^{6}$ Architects \& Engineers for 9/11 Truth, Berkeley, CA 94704, USA \\ ${ }^{7}$ International Center for 9/11 Studies, Dallas, TX 75231, USA
}

\begin{abstract}
We have discovered distinctive red/gray chips in all the samples we have studied of the dust produced by the destruction of the World Trade Center. Examination of four of these samples, collected from separate sites, is reported in this paper. These red/gray chips show marked similarities in all four samples. One sample was collected by a Manhattan resident about ten minutes after the collapse of the second WTC Tower, two the next day, and a fourth about a week later. The properties of these chips were analyzed using optical microscopy, scanning electron microscopy (SEM), X-ray energy dispersive spectroscopy (XEDS), and differential scanning calorimetry (DSC). The red material contains grains approximately $100 \mathrm{~nm}$ across which are largely iron oxide, while aluminum is contained in tiny plate-like structures. Separation of components using methyl ethyl ketone demonstrated that elemental aluminum is present. The iron oxide and aluminum are intimately mixed in the red material. When ignited in a DSC device the chips exhibit large but narrow exotherms occurring at approximately $430{ }^{\circ} \mathrm{C}$, far below the normal ignition temperature for conventional thermite. Numerous iron-rich spheres are clearly observed in the residue following the ignition of these peculiar red/gray chips. The red portion of these chips is found to be an unreacted thermitic material and highly energetic.
\end{abstract}

Keywords: Scanning electron microscopy, X-ray energy dispersive spectroscopy, Differential scanning calorimetry, DSC analysis, World Trade Center, WTC dust, 9/11, Iron-rich microspheres, Thermite, Super-thermite, Energetic nanocomposites, Nano-thermite.

\section{INTRODUCTION}

The destruction of three skyscrapers (WTC 1,2 and 7) on September 11, 2001 was an immensely tragic catastrophe that not only impacted thousands of people and families directly, due to injury and loss of life, but also provided the motivation for numerous expensive and radical changes in domestic and foreign policy. For these and other reasons, knowing what really happened that fateful day is of grave importance.

A great deal of effort has been put forth by various government-sponsored and -funded investigations, which led, in large part, to the reports released by FEMA [1] and NIST [2]. Other studies of the destruction have been less well

*Address correspondence to these authors (NH) Department of Chemistry, University of Copenhagen, Copenhagen, DK-2100, Denmark;

Tel: (+45)35321846; Fax: (+45)35320460; E-mail: harrit@nano.ku.dk, (SEJ) at S\&J Scientific Co., Provo, UT, 84606, USA; Tel: 801-735-5885; E-mail: Hardevidence@gmail.com publicized but are no less important to the outstanding obligation that remains to the victims of that tragedy, to determine the whole truth of the events of that day [3-10]. A number of these studies have appropriately focused attention on the remaining physical material, and on available photographs and video footage, as sources of evidence still in public hands, relating to the method of destruction of the three skyscrapers.

The collapses of the three tallest WTC buildings were remarkable for their completeness, their near free-fall speed $[11]$ their striking radial symmetry $[1,12]$ and the surprisingly large volume of fine toxic dust [13] that was generated. In order to better understand these features of the destruction, the authors initiated an examination of this dust. In June 2007 , Dr. Steven Jones observed distinctive bi-layered chips, with both a red and a gray layer, in a sample of the WTC dust. Initially, it was suspected these might be dried paint chips, but after closer inspection and testing, it was shown that this was not the case. Further testing was then performed on the red/gray chips in an attempt to ascertain their compo- 
sition and properties. The authors also obtained and examined additional samples of WTC dust which had been collected by independent observers on, or very soon after, 9/11. All of the samples examined contained these very small, peculiar red/gray chips. Previous studies discussing observations of the WTC dust include reports by the RJ Lee Company [14], the U.S. Geological Survey (USGS) [15], McGee et al. [13] and Lioy et al. [16] Some of these studies confirmed the finding of iron-rich microspheres, which are also peculiar [5, 8, 11, 13-15] but the red/gray chips analyzed in this study have apparently not been discussed in previously published reports. It is worth emphasizing that one sample was collected about ten minutes after the collapse of the second Tower, so it cannot possibly have been contaminated by clean-up operations [17].

\section{MATERIALS AND METHODS}

\section{Provenance of the Samples Analyzed for this Report}

In a paper presented first online in autumn 2006 regarding anomalies observed in the World Trade Center destruc- tion [6], a general request was issued for samples of the WTC dust. The expectation at that time was that a careful examination of the dust might yield evidence to support the hypothesis that explosive materials other than jet fuel caused the extraordinarily rapid and essentially total destruction of the WTC buildings.

It was learned that a number of people had saved samples of the copious, dense dust, which spread and settled across Manhattan. Several of these people sent portions of their samples to members of this research group. This paper discusses four separate dust samples collected on or shortly after 9/11/2001. Each sample was found to contain red/gray chips. All four samples were originally collected by private citizens who lived in New York City at the time of the tragedy. These citizens came forward and provided samples for analysis in the public interest, allowing study of the $9 / 11$ dust for whatever facts about the day might be learned from the dust. A map showing the locations where the four samples were collected is presented as Fig. (1).

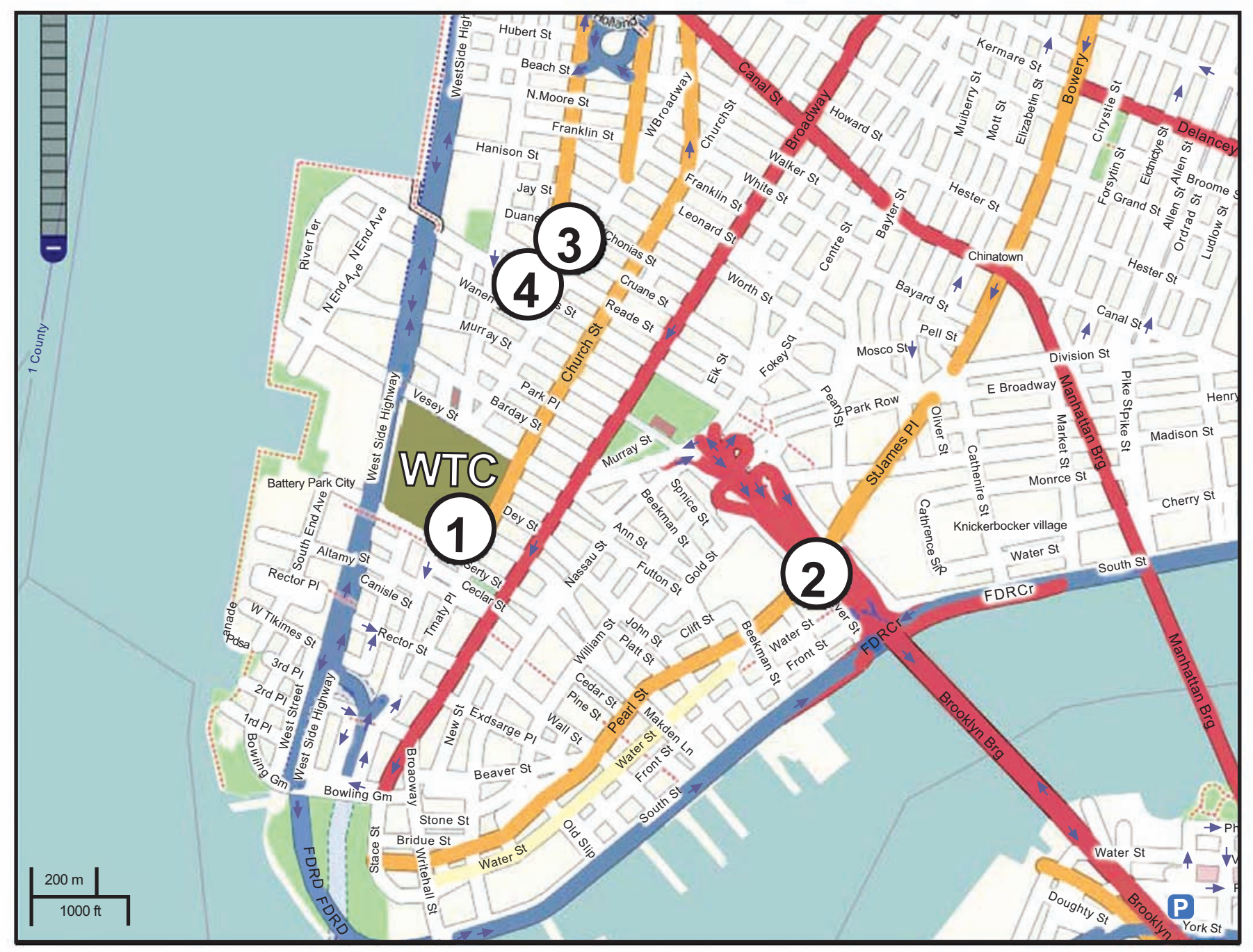

Fig. (1). Map showing collection locations of dust samples analyzed in this study with respect to the location of the WTC complex (marked area near location 1). 1: MacKinlay (113 Cedar St./110 Liberty St); 2: Delessio/Breidenbach (Brooklyn Bridge); 3 : Intermont (16 Hudson St); 4: White (1 Hudson St). (Base map courtesy of http://www.openstreetmap.org; copyright terms at http://creativecommons.org/licenses/ by-sa/2.0/). 
The earliest-collected sample came from Mr. Frank Delessio who, according to his videotaped testimony [17], was on the Manhattan side of the Brooklyn Bridge about the time the second tower, the North Tower, fell to the ground. He saw the tower fall and was enveloped by the resulting thick dust which settled throughout the area. He swept a handful of the dust from a rail on the pedestrian walkway near the end of the bridge, about ten minutes after the fall of the North Tower. He then went to visit his friend, Mr. Tom Breidenbach, carrying the dust in his hand, and the two of them discussed the dust and decided to save it in a plastic bag. On 11/15/2007, Breidenbach sent a portion of this dust to Dr. Jones for analysis. Breidenbach has also recorded his testimony about the collection of this dust sample on videotape [17]. Thus, the Delessio/Breidenbach sample was collected about ten minutes after the second tower collapsed. It was, therefore, definitely not contaminated by the steelcutting or clean-up operations at Ground Zero, which began later. Furthermore, it is not mixed with dust from WTC 7, which fell hours later.

On the morning of 9/12/2001, Mr. Stephen White of New York City entered a room in his apartment on the 8th floor of 1 Hudson Street, about five blocks from the WTC. He found a layer of dust about an inch thick on a stack of folded laundry near a window which was open about 4 inches $(10 \mathrm{~cm})$. Evidently the open window had allowed a significant amount of dust from the WTC destruction the day before to enter the room and cover the laundry. He saved some of the dust and, on $2 / 02 / 2008$, sent a sample directly to Dr. Jones for analysis.

Another sample was collected from the apartment building at 16 Hudson Street by Mr. Jody Intermont at about $2 \mathrm{pm}$ on $9 / 12 / 2001$. Two small samples of this dust were simultaneously sent to Dr. Jones and to Kevin Ryan on 2/02/2008 for analysis. Intermont sent a signed affidavit with each sample verifying that he had personally collected the (nowsplit) sample; he wrote:

\begin{abstract}
"This dust, which came from the 'collapsed' World Trade Center Towers, was collected from my loft at the corner of Reade Street and Hudson Street on September 12, 2001. I give permission to use my name in connection to this evidence". [Signed 31 January 2008 in the presence of a witness who also signed his name].
\end{abstract}

On the morning of 9/11/2001, Ms. Janette MacKinlay was in her fourth-floor apartment at 113 Cedar St./110 Liberty St. in New York City, across the street from the WTC plaza. As the South Tower collapsed, the flowing cloud of dust and debris caused windows of her apartment to break inward and dust filled her apartment. She escaped by quickly wrapping a wet towel around her head and exiting the building. The building was closed for entry for about a week. As soon as Ms. MacKinlay was allowed to re-enter her apartment, she did so and began cleaning up. There was a thick layer of dust on the floor. She collected some of it into a large sealable plastic bag for possible later use in an art piece. Ms. MacKinlay responded to the request in the 2006 paper by Dr. Jones by sending him a dust sample. In No- vember 2006, Dr. Jones traveled to California to visit Ms. MacKinlay at her new location, and in the company of several witnesses collected a second sample of the WTC dust directly from her large plastic bag where the dust was stored. She has also sent samples directly to Dr. Jeffrey Farrer and Kevin Ryan. Results from their studies form part of this report.

Another dust sample was collected by an individual from a window sill of a building on Potter Street in NYC. He has not given permission for his name to be disclosed, therefore his material is not included in this study. That sample, however, contained red/gray chips of the same general composition as the samples described here.

\section{Chip Size, Isolation, and Examination}

For clarification, the dust samples collected and sent to the authors by Ms. Janette MacKinlay will be sample 1; the sample collected by Mr. Frank Delassio, or the Delassio/Breidenbach sample, will be sample 2; the sample collected by Mr. Jody Intermont will be sample 3; and the sample collected by Mr. Stephen White will be sample 4. The red/gray chips are attracted by a magnet, which facilitates collection and separation of the chips from the bulk of the dust. A small permanent magnet in its own plastic bag was used to attract and collect the chips from dust samples. The chips are typically small but readily discernible by eye due to their distinctive color. They are of variable size with major dimensions of roughly 0.2 to $3 \mathrm{~mm}$. Thicknesses vary from roughly 10 to 100 microns for each layer (red and gray). Samples of WTC dust from these and other collectors have been sent directly from collectors to various scientists (including some not on this research team) who have also found such red/gray chips in the dust from the World Trade Center destruction.

An FEI XL30-SFEG scanning electron microscope (SEM) was used to perform secondary-electron (SE) imaging and backscattered electron (BSE) imaging. The SE imaging was used to look at the surface topography and porosity of the red/gray chips, while the BSE imaging was used to distinguish variations in average atomic number, $\mathrm{Z}$. The microscope was also equipped with an EDAX X-ray energy dispersive spectrometry (XEDS) system. The XEDS system uses a silicon detector (SiLi) with resolution better than 135 $\mathrm{eV}$. The spectrum resolution was set to $10 \mathrm{eV}$ per channel. Operating conditions for the acquired XEDS spectra were 20 $\mathrm{keV}$ beam energy (unless otherwise specified) and 40-120 second acquisition time (livetime). XEDS maps were acquired using the same system at a beam energy of $10 \mathrm{keV}$.

For general surface analysis in the SEM, dust samples were mounted to carbon conductive tabs. The samples were left unwashed and uncoated unless otherwise specified. In order to more closely observe the characteristics of the red and gray layers, and to eliminate the possibility of surface contamination from other dust particles, several red/gray chips from each of the four WTC dust samples were fractured. The clean, cross-section surfaces were then studied by BSE imaging and XEDS. 
Some samples were also tested in a differential scanning calorimeter (Netzsch DSC 404C) to measure heat flow into or out of the red/gray chips. The DSC tests were conducted with a linear heating rate of $10{ }^{\circ} \mathrm{C}$ per minute up to a temperature of $700{ }^{\circ} \mathrm{C}$. During heating, the samples were contained in alumina pans and air was allowed to flow at 55 milliliters per minute during the heating. The plots were generated by acquiring data points at a rate of 20 points per ${ }^{\circ} \mathrm{C}$ or 200 points per minute. The equipment was calibrated to display the data in watts per gram. The plots were set to display positive heat flow out of the sample such that exothermic behavior of the sample would yield a peak and endothermic behavior a trough.

The dust samples were also examined by visible-light microscopy (VLM) through a Nikon Epiphot 200 stereomicroscope, an Olympus BX60 stereomicroscope and a Nikon Labophot microscope and camera.

\section{RESULTS}

\section{Characterization of the Red/Gray Chips}

Red/gray chips were found in all of the dust samples collected. An analysis of the chips was performed to assess the similarity of the chips and to determine the chemistry and materials that make up the chips. Fig. (2) displays photomi- crographs of red/gray chips from each of the four WTC dust samples. Note the scale marker in each image as they were acquired at different magnifications. At approximately $2.5 \mathrm{~mm}$ in length, the chip in Fig. (2a) was one of the larger chips collected. The mass of this chip was approximately 0.7 $\mathrm{mg}$. All of the chips used in the study had a gray layer and a red layer and were attracted by a magnet. The inset image in Fig. (2d) shows the chip in cross section, which reveals the gray layer. The gray layer is also partially visible in Fig. (2b). Similarities between the samples are already evident from these photographs.

Fig. (3) shows three images for comparison of views of the same set of chips using different methods. Fig. (3a) is a VLM photomicrograph of a group of particles, which shows the red material and in some cases the adhering gray material. Fig. (3b, c) are, respectively, a secondary electron (SE) image and a backscattered electron (BSE) image of the same group of particles, using a scanning electron microscope (SEM) without a conductive coating over the sample. It can be seen in the SE image that the red layer of the particles has very bright regions caused by a slight accumulation of charge under the electron beam, owing to the relatively poor conductivity of the red layer (see Discussion section). The BSE image shows the red layer darker than the gray layer,

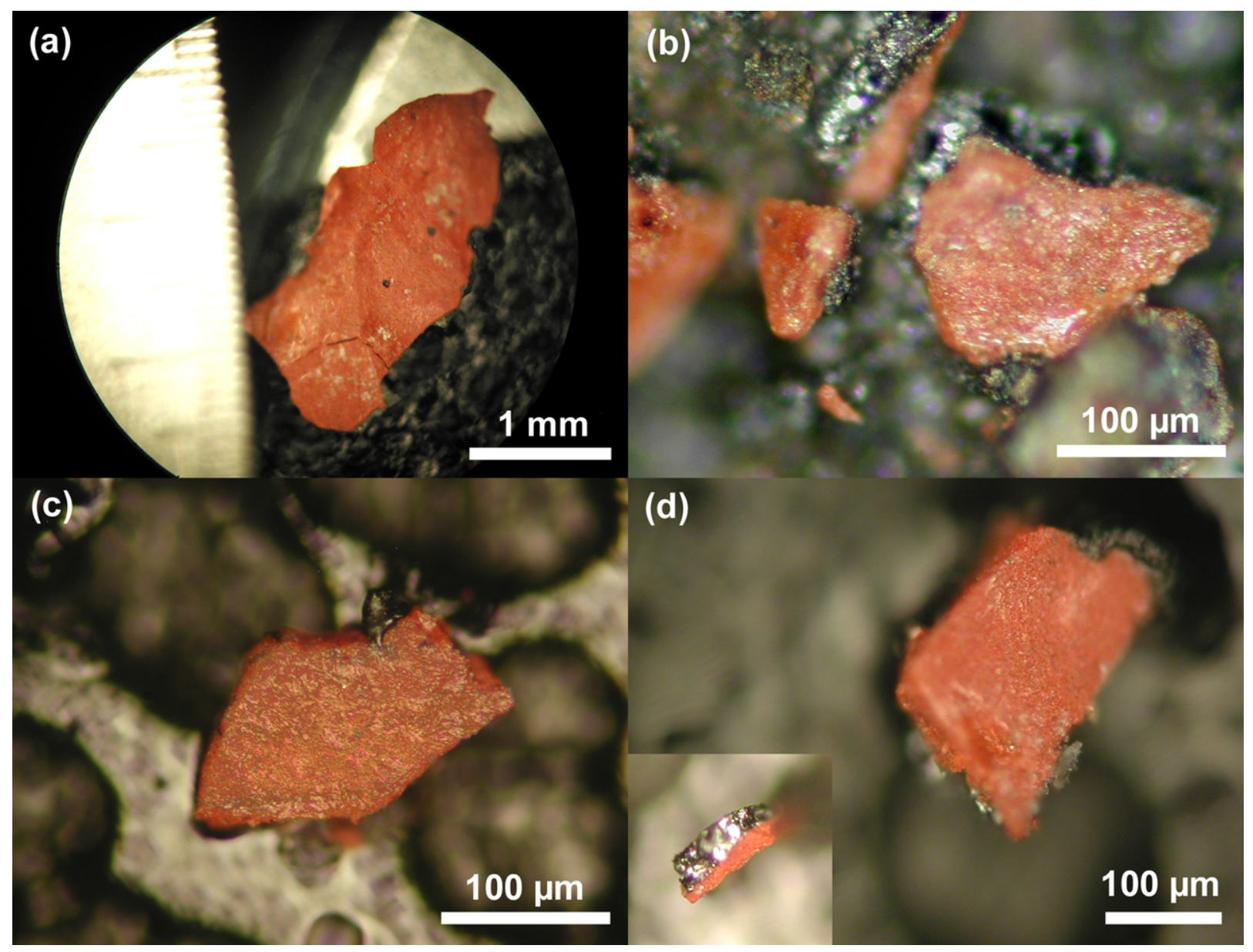

Fig. (2). Photomicrographs of red/gray chips from samples 1-4 of the WTC dust involved in this study, shown in (a)-(d) respectively. The inset in (d) shows the chip edge on, which reveals the gray layer. The red/gray chips are mounted on an aluminum pedestal, using a carbon conductive tab, for viewing in the scanning electron microscope (SEM). 


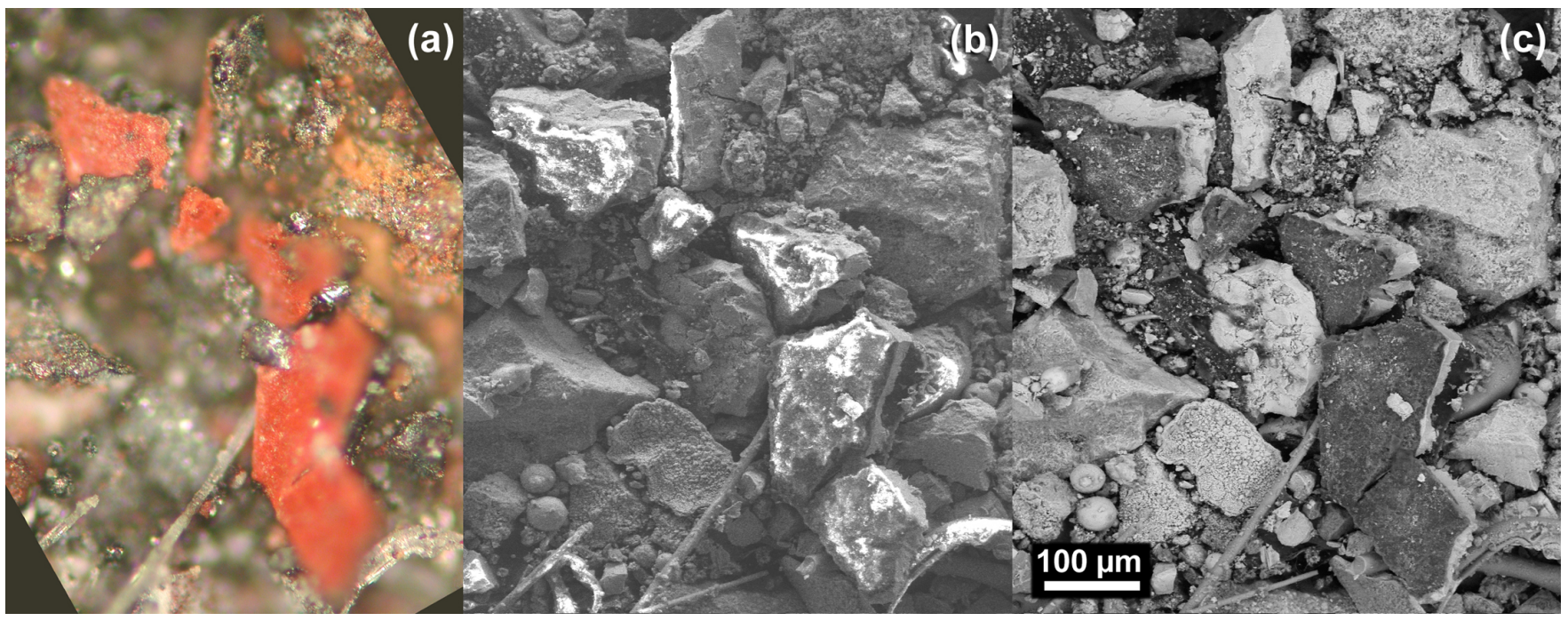

Fig. (3). A series of images of the same group of particles extracted by magnet from sample 2. The color photomicrograph in (a), obtained by VLM, locates and identifies the red/gray particles. An SE image (b) acquired by SEM gives a better indication of size and shape of the particles, and a BSE image (c) shows, by grayscale intensity, the difference in average atomic number between the red layer, gray layer and other dust particles.

indicating that the red layer is composed of material that has a relatively lower average atomic number than the gray layer.

A higher-magnification BSE image of the corner of one of the chips, shown in Fig. (4), allows for closer examination of the difference in grayscale intensity of the two layers and confirms the higher average atomic number of the gray layer. The red material also shows specks and other heterogeneities, in marked contrast to the smooth gray layer.
Newly fractured cross sections of red/gray chips from the four different dust samples are shown by BSE imaging in Fig. (5). These four cross sections are representative of all the red/gray chips studied from the dust samples. The BSE images illustrate the finding that all of the red layers studied contained small bright particles or grains characterized by a high average atomic number. The size and presence of the particles was found to be consistent throughout the layers, but the concentration of the particles was found to vary locally, as can be seen from the images.

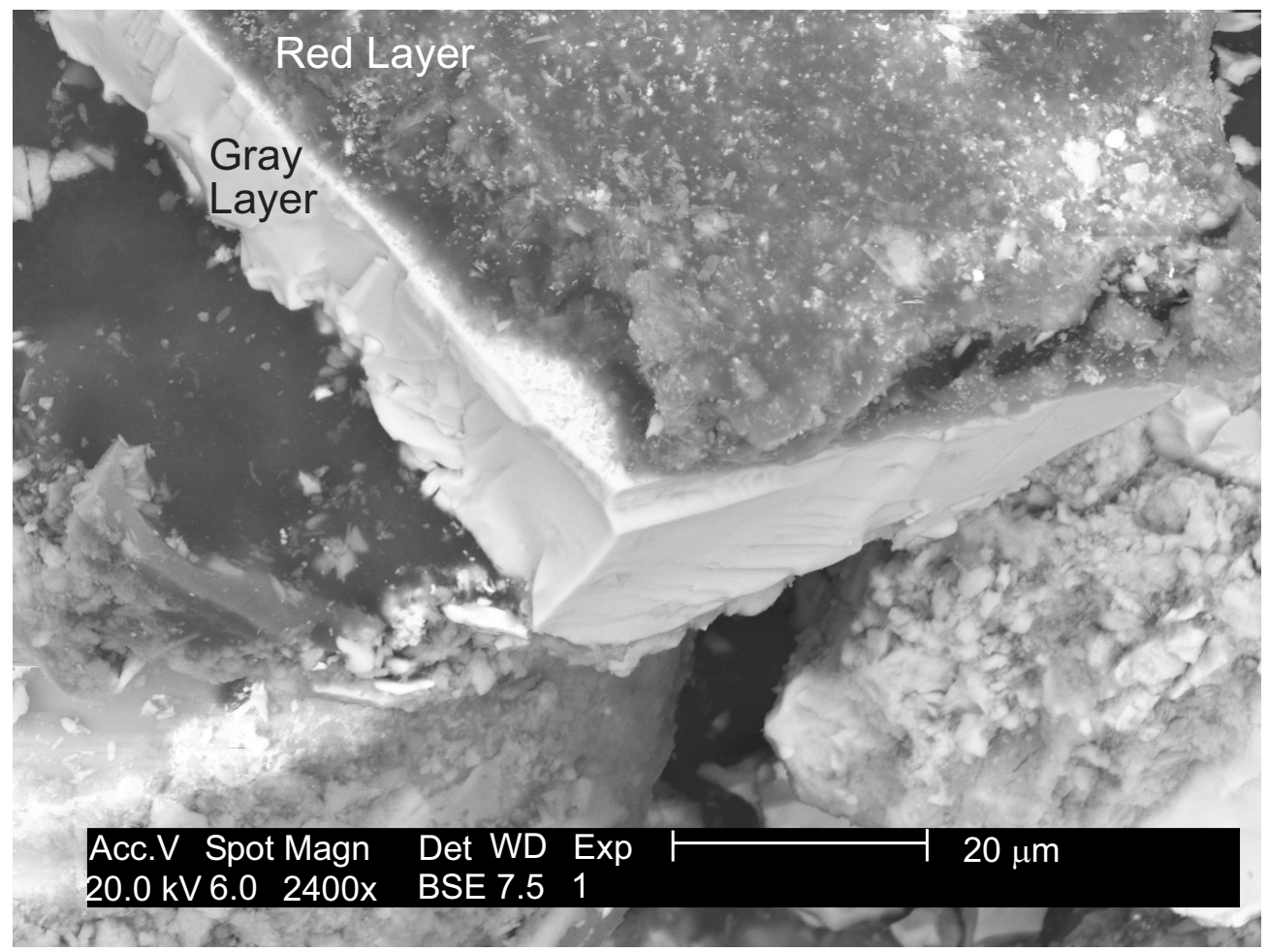

Fig. (4). Higher magnification BSE image of one of the chips in previous image. The red layer appears darker and is on top of the gray layer. 


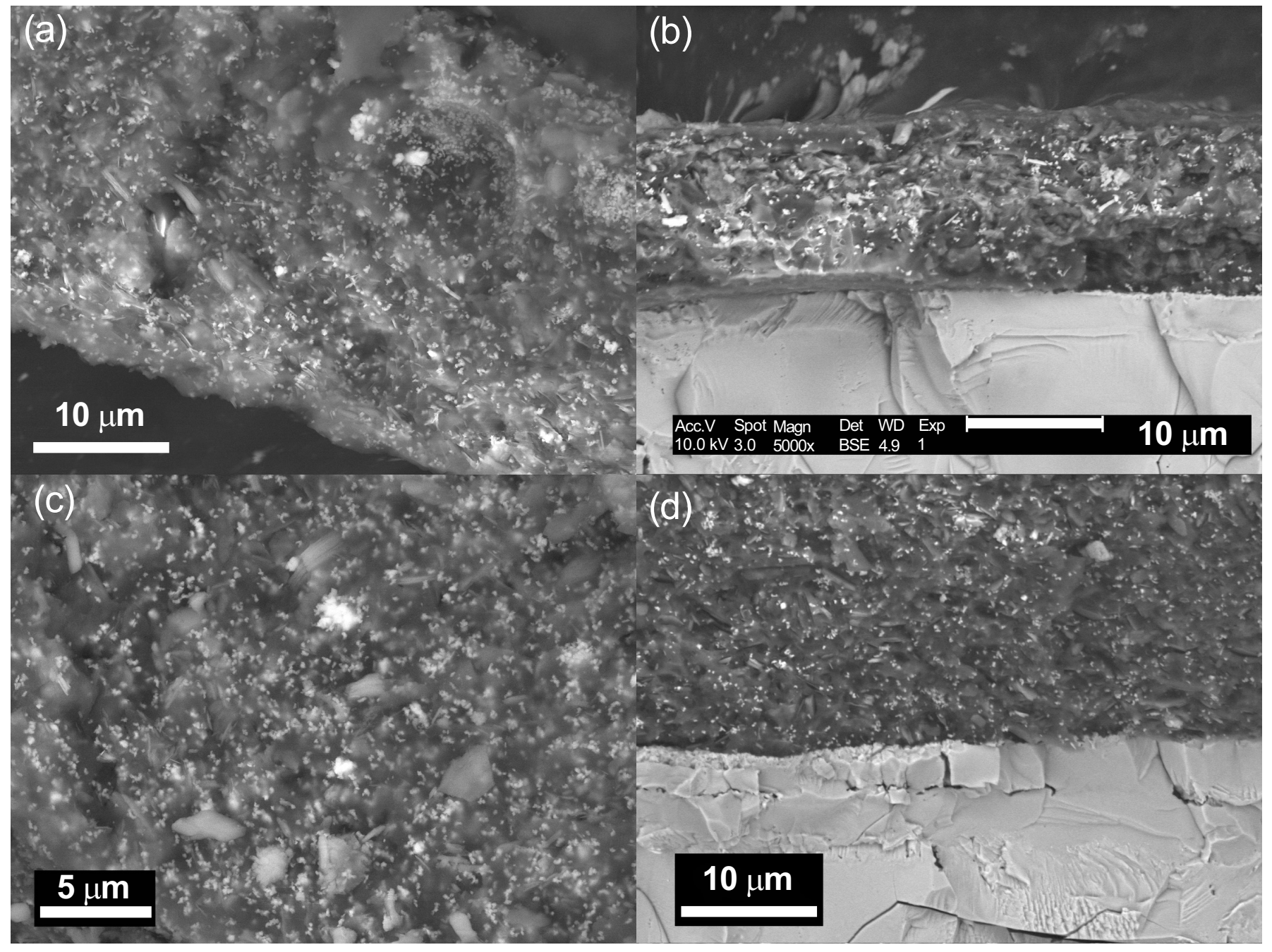

Fig. (5). BSE images of cross sections of red/gray chips from samples 1-4 shown in (a)-(d) respectively. The cross sections from sample 2 (b) and 4 (d) also show the adhering gray layer.

X-ray energy-dispersive spectroscopy (XEDS) analyses of both the red and gray layers from cross sections prepared from the four dust samples were performed and representative spectra are shown in Figs. $(6,7)$. The four spectra in Fig. (6) indicate that the gray layers are consistently characterized by high iron and oxygen content including a smaller amount of carbon. The chemical signatures found in the red layers are also quite consistent (Fig. 7), each showing the presence of aluminum ( $\mathrm{Al})$, silicon $(\mathrm{Si})$, iron $(\mathrm{Fe})$ and oxygen $(\mathrm{O})$, and a significant carbon $(\mathrm{C})$ peak as well.

At still higher magnifications, BSE imaging of the red layer illustrates the similarity between the different dust samples. BSE images of small but representative portions of each red-layer cross section are shown in Fig. (8). The results indicate that the small particles with very high BSE intensity (brightness) are consistently $100 \mathrm{~nm}$ in size and have a faceted appearance. These bright particles are seen intermixed with plate-like particles that have intermediate BSE intensity and are approximately $40 \mathrm{~nm}$ thick and up to about 1 micron across. Furthermore, by comparing the BSE image in Fig. (8a) to the SE image in Fig. (9), it can be seen that all of the particles are embedded in an unstructured matrix which gives a dark BSE intensity.
XEDS maps of the cross-section surface of the red layer were acquired at a beam energy of $10 \mathrm{kV}$. The acquisition area of the maps is shown by the BSE image in Fig. (10a). The XEDS maps, several of which are shown in Fig. (10b-f), indicate by color, the degree to which the particular element is present at or near the surface from point to point across the area. The results indicate that the smaller particles with very bright BSE intensity are associated with the regions of high $\mathrm{Fe}$ and $\mathrm{O}$. The plate-like particles with intermediate BSE intensity appear to be associated with the regions of high $\mathrm{Al}$ and Si. The O map (d) also indicates oxygen present, to a lesser degree, in the location of the $\mathrm{Al}$ and $\mathrm{Si}$. However, it is inconclusive from these data whether the $\mathrm{O}$ is associated with $\mathrm{Si}$ or $\mathrm{Al}$ or both. The carbon map appears less definitive, that is, it does not appear to be associated with a particular particle or group of particles, but rather with the matrix material.

In order to learn more from these findings, a focused electron beam was placed directly onto the different particles, and the XEDS data were collected. By placing the beam on a cluster of plate-like particles, the spectrum in Fig. (11a) was generated. The spectrum in Fig. (11b) was acquired 


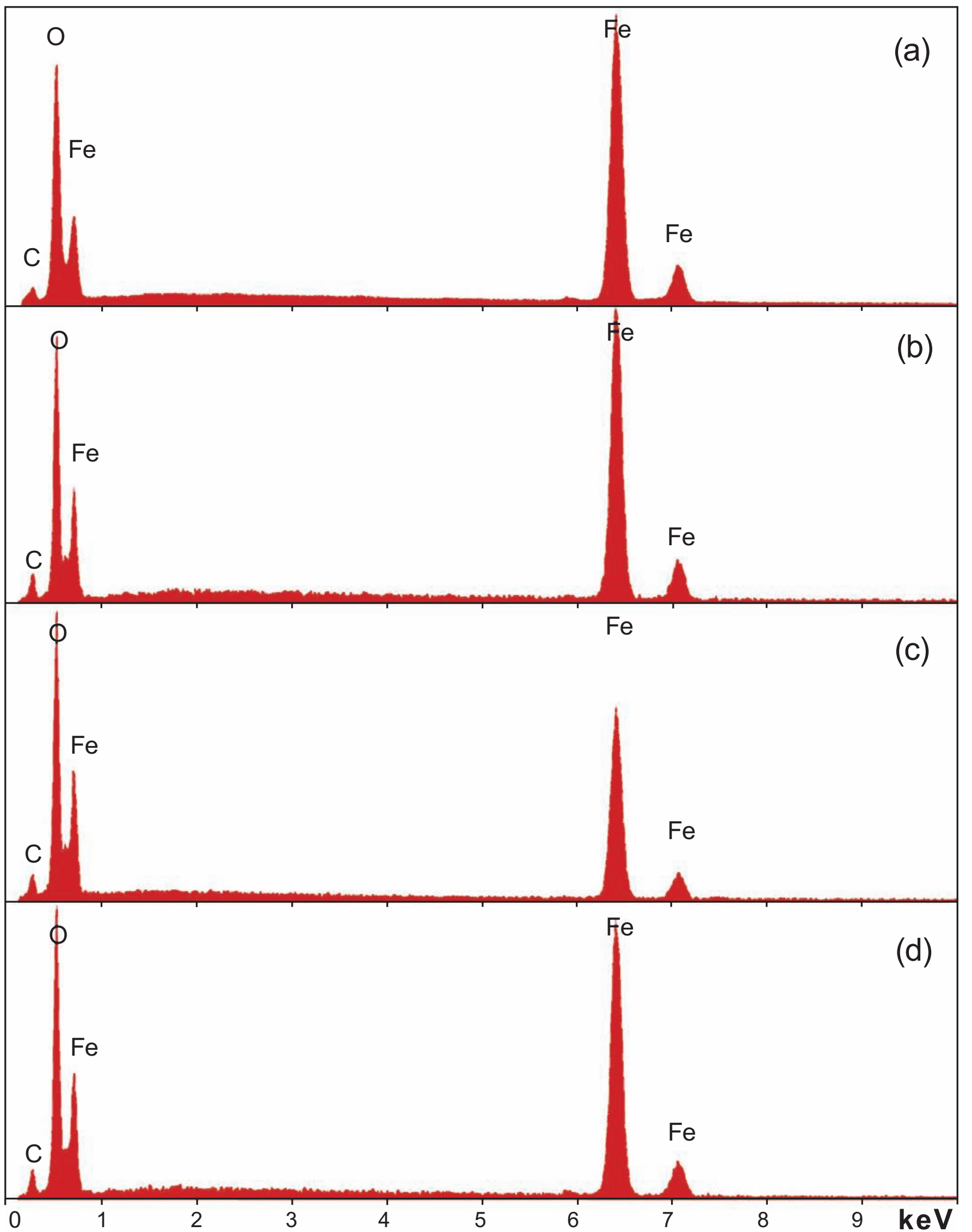

Fig. (6). XEDS spectra obtained from the gray layers from each of the four WTC dust samples, with (a) corresponding to sample 1, and so on (b-d). 


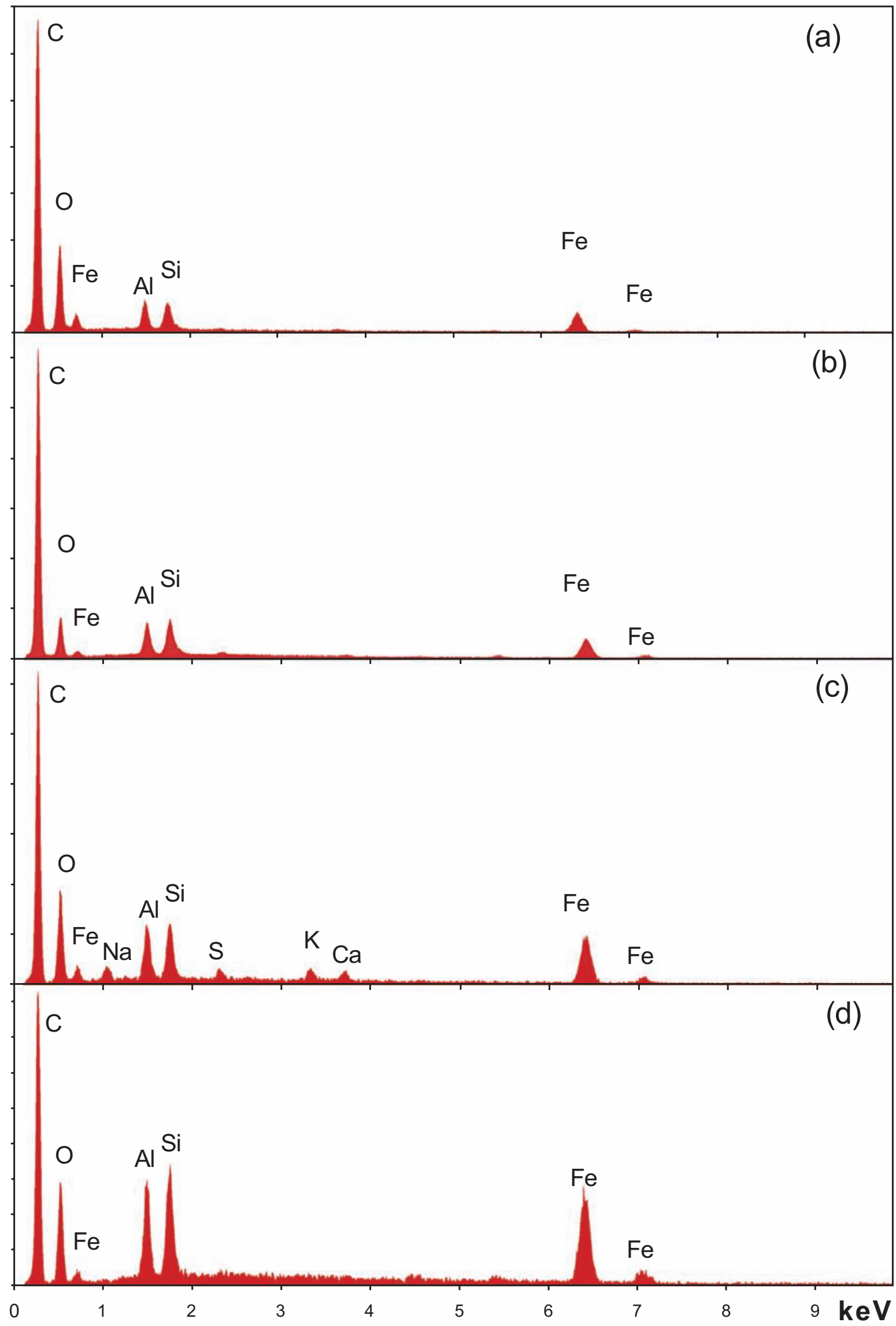

Fig. (7). XEDS spectra obtained from the red layers from each of the four WTC dust samples, with (a) corresponding to sample 1 and so on (b-d). 


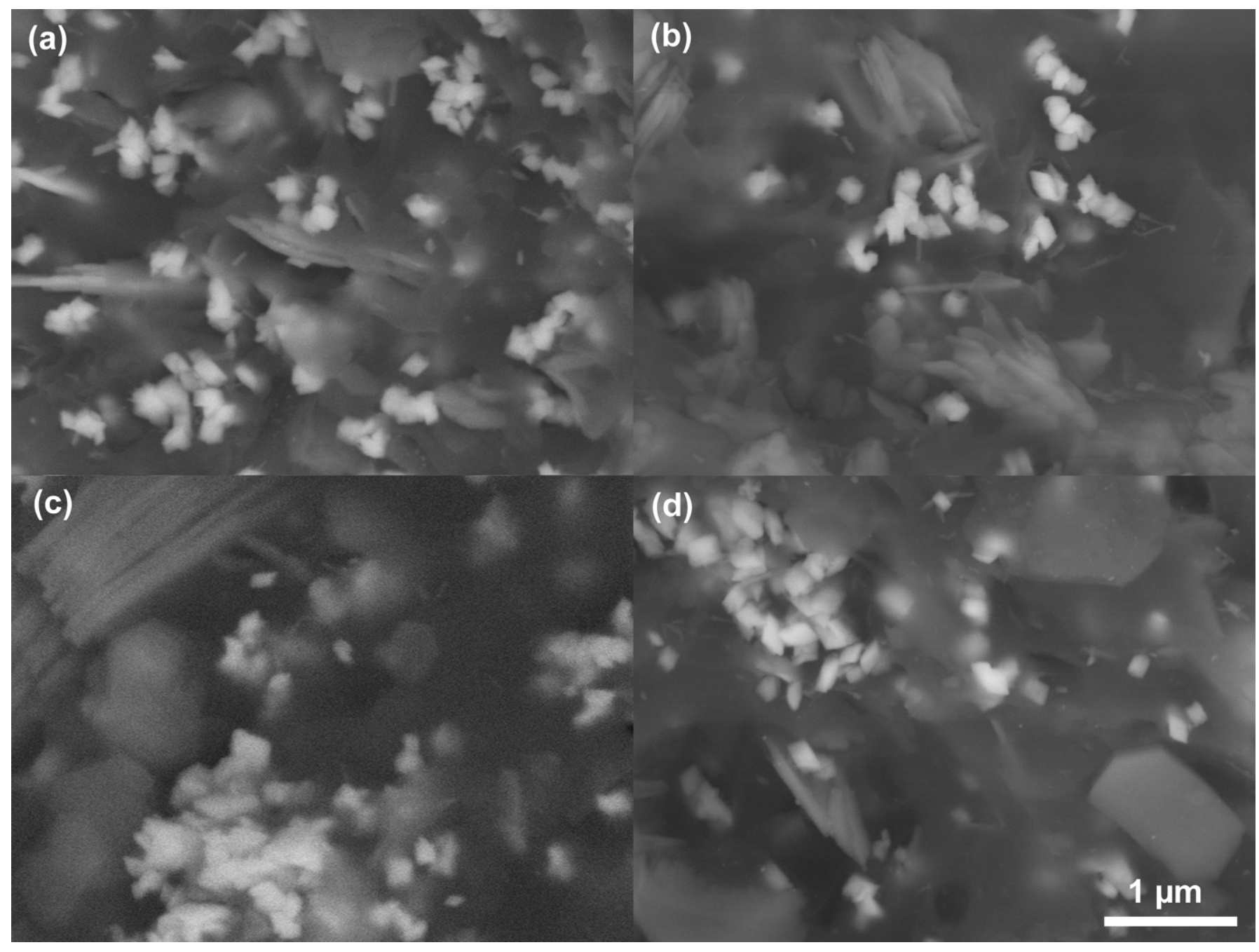

Fig. (8). BSE images of cross sections of the red layer from each of the dust samples 1-4 shown in (a)-(d) respectively.

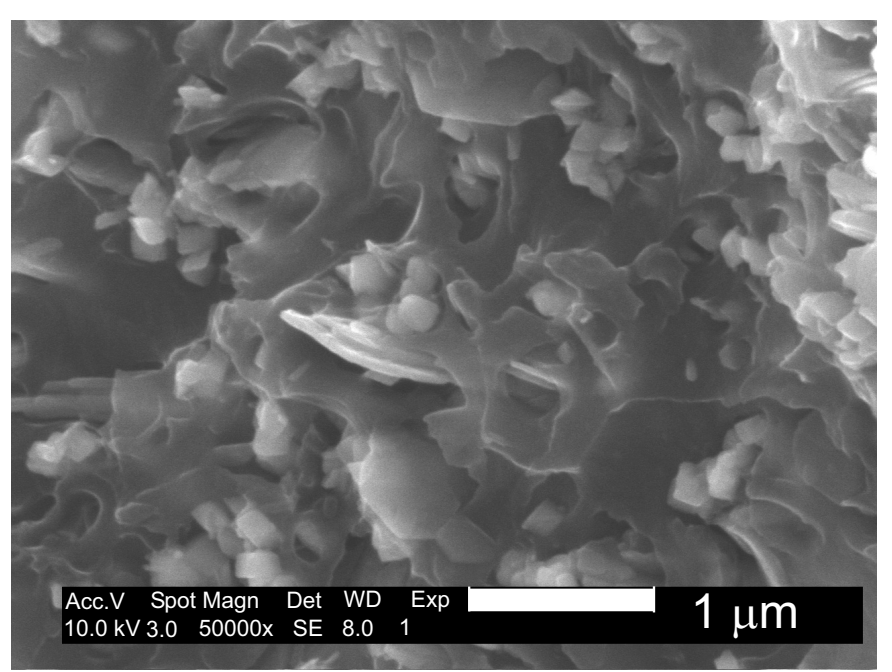

Fig. (9). SE image of the cross section shown in Fig. (8a).

from a cluster of the smaller bright faceted grains. Again it was observed that the thin sheet-like particles are rich in $\mathrm{Al}$ and $\mathrm{Si}$ whereas the bright faceted grains are rich in Fe. Both spectra display significant carbon and oxygen, which may be partially due to the beam spreading and receiving an overlapping X-ray signal from the matrix material as well as particles below the surface. The beam energy $(20 \mathrm{keV})$ is such that the volume of material from which the X-ray signal is generated is larger than the particles. Hence, some Al and Si are seen in Fig. (11b) which may not be inherent in the faceted grains, and some Fe is seen in Fig. (11a), which may not be inherent in the plate-like particles.

The consistently rhombic-shaped, faceted appearance of the iron-rich grains strongly suggests that they are crystalline. From these data, it is determined that the red/gray chips from different WTC dust samples are extremely similar in their chemical and structural makeup. It is also shown that within the red layer there is an intimate mixing of the Fe-rich grains and Al/Si plate-like particles and that these particles are embedded in a carbon-rich matrix.

\section{Test Using Methyl Ethyl Ketone Solvent}

By employing some means to separate the different components of the material, the chemical compositions of the different particles in the red layer were more accurately 


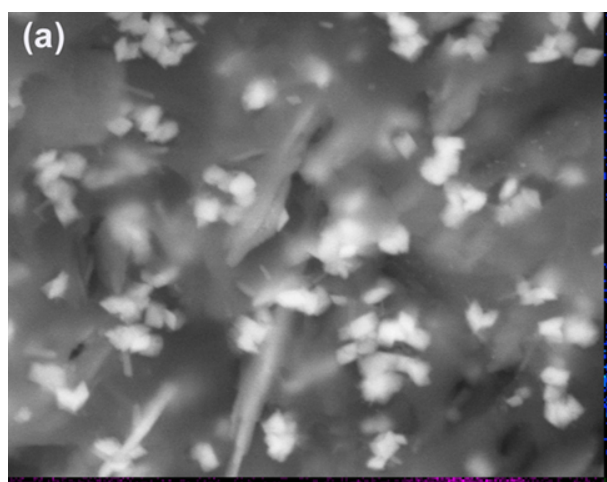

(c)

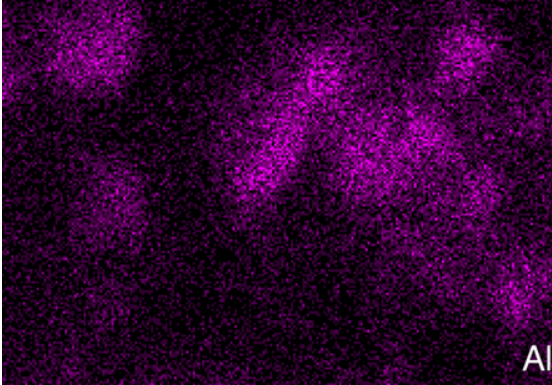

(e)

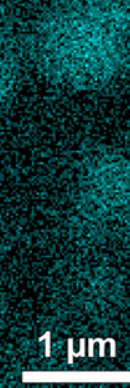

\section{(b)}

$\mathrm{Fe}$

(d)

O

(f)

Fig. (10). This shows a BSE image (a) and XEDS maps (b-f) of the red-layer cross section of a red/gray chip from dust sample 1. The elements displayed are: (b) Fe, (c) $\mathrm{Al}$, (d) $\mathrm{O}$, (e) $\mathrm{Si}$, and (f) $\mathrm{C}$.

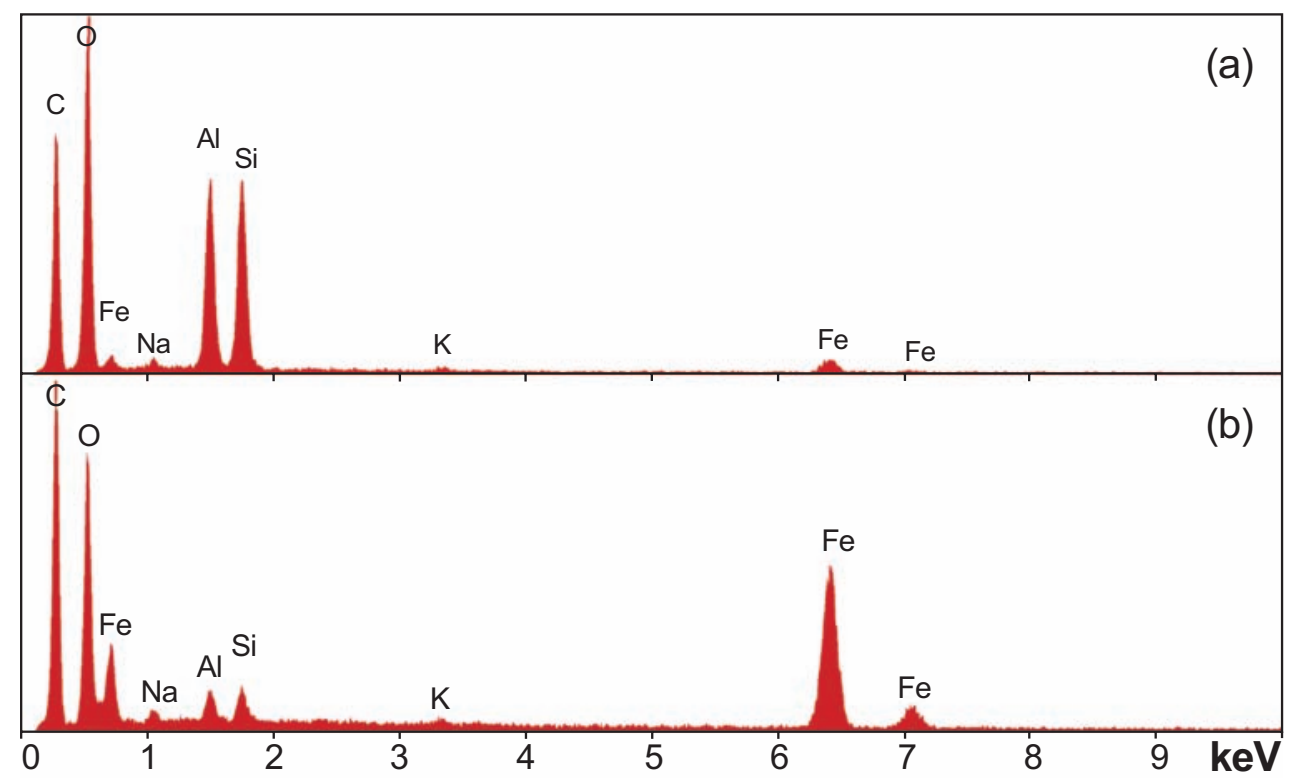

Fig. (11). XEDS spectra showing the elemental compositions of a grouping of thin platelets (a) and of a grouping of whitish particles (b), as seen in the high-magnification images of red layers (see Fig. $(\mathbf{8})$ ). 
determined. The initial objective was to compare the behavior of the red layer with paint when soaked in a strong organic solvent known to soften and dissolve paint. Red/gray chips were soaked in methyl ethyl ketone (MEK) for 55 hours with frequent agitation and subsequently dried in air over several days. The chips showed significant swelling of the red layer, but with no apparent dissolution. In marked contrast, paint chips softened and partly dissolved when similarly soaked in MEK. It was discovered in this process that a significant migration and segregation of aluminum had occurred in the red-chip material. This allowed us to assess whether some of the aluminum was in elemental form.

The chip that was used for this experiment was extracted from dust sample 2 and is shown in the images below. Fig. (12a) shows an SE image of the chip prior to the MEK treatment. It is positioned with the interface between the red and gray layers nearly parallel to the plane of the image. Fig. (12b) shows a BSE image of the chip after the MEK soak. Note that the chip fractured during the MEK treatment and handling. In this image the red layer and gray layer are side by side so that the interface between the layers is edge-on (perpendicular to the plane of the image) with the gray layer on the right. The red layer of the chip was found, by visual inspection, to have swelled out from the gray layer by a fac-
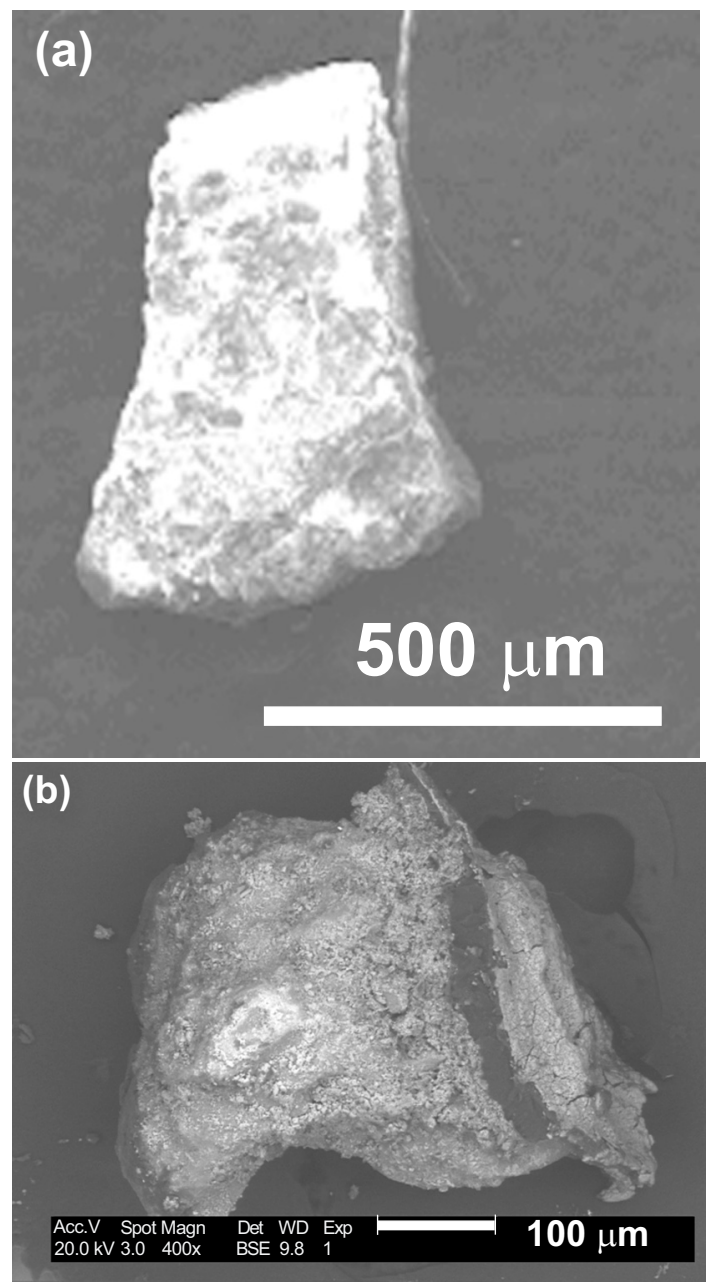

Fig. (12). SE images of the red/gray chip that was soaked in methyl ethyl ketone for 55 hours, (a) prior to and (b) after MEK soaking. tor of roughly 5 times its original thickness. The photomicrograph shown in Fig. (13) also shows the chip after the MEK soak. The red layer can be seen extending out from the gray layer.

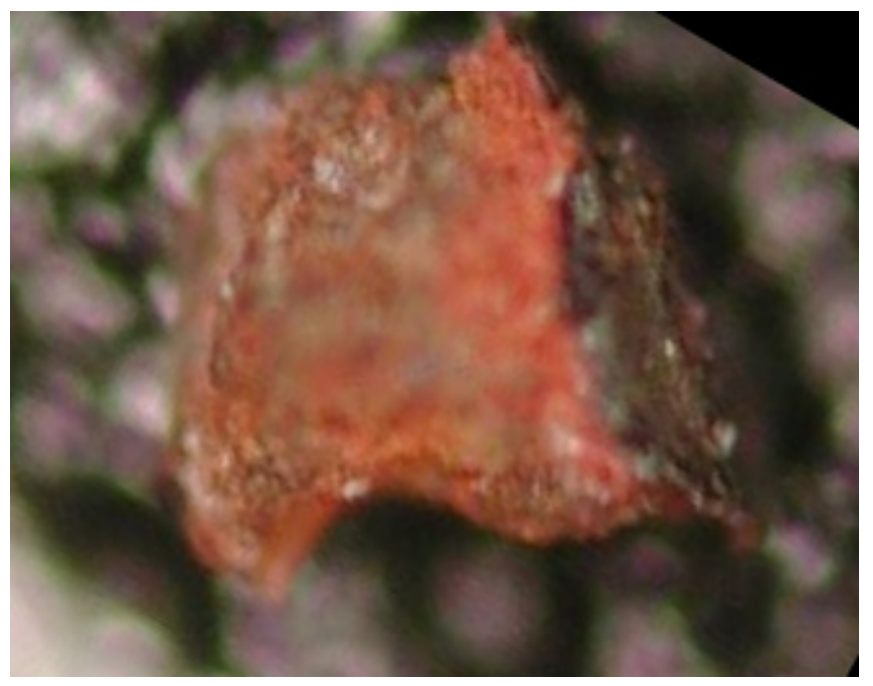

Fig. (13). Photomicrograph of the MEK treated chip.

Prior to soaking the chip in MEK an XEDS spectrum was acquired from an area of the red-layer surface. The resulting spectrum, shown in Fig. (14), produced the expected peaks for $\mathrm{Fe}, \mathrm{Si}, \mathrm{Al}, \mathrm{O}$, and $\mathrm{C}$. Other peaks included calcium, sulfur, zinc, chromium and potassium. The occurrence of these elements could be attributed to surface contamination due to the fact that the analysis was performed on the as-collected surface of the red layer. The large $\mathrm{Ca}$ and $\mathrm{S}$ peaks may be due to contamination with gypsum from the pulverized wallboard material in the buildings.

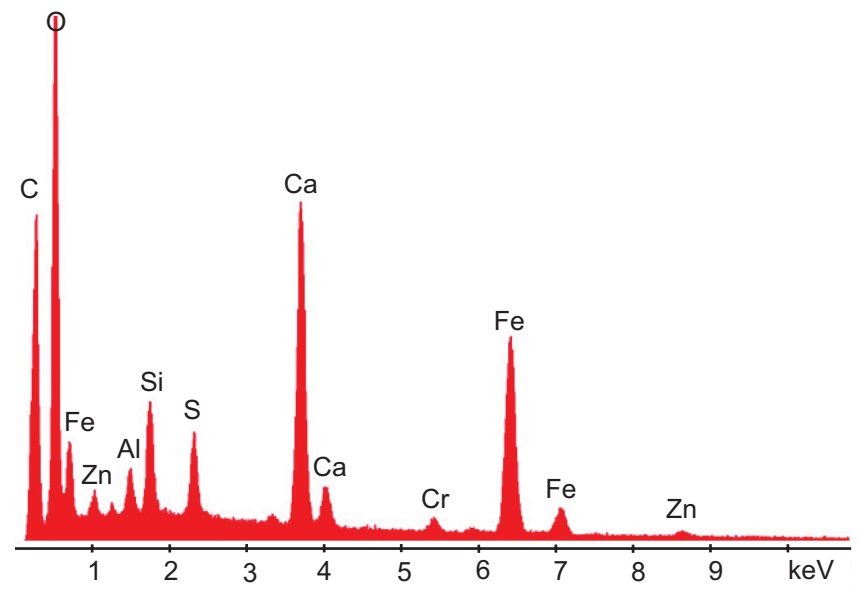

Fig. (14). XEDS spectrum of red side before soaking in MEK. Notice the presence of $\mathrm{Zn}$ and $\mathrm{Cr}$, which are sometimes seen in the red layers. The large $\mathrm{Ca}$ and $\mathrm{S}$ peaks may be due to surface contamination with wallboard material.

XEDS maps were acquired from the swollen red material at a beam energy of $10 \mathrm{kV}$, in order to determine the locations of various elements following the MEK treatment. The data shown in Fig. (15) illustrate regions where iron, aluminum and silicon are concentrated. Furthermore, the data indicate that wherever silicon or iron is concentrated, oxygen is also concentrated. On the other hand, there also exist regions where the aluminum is concentrated but where the 


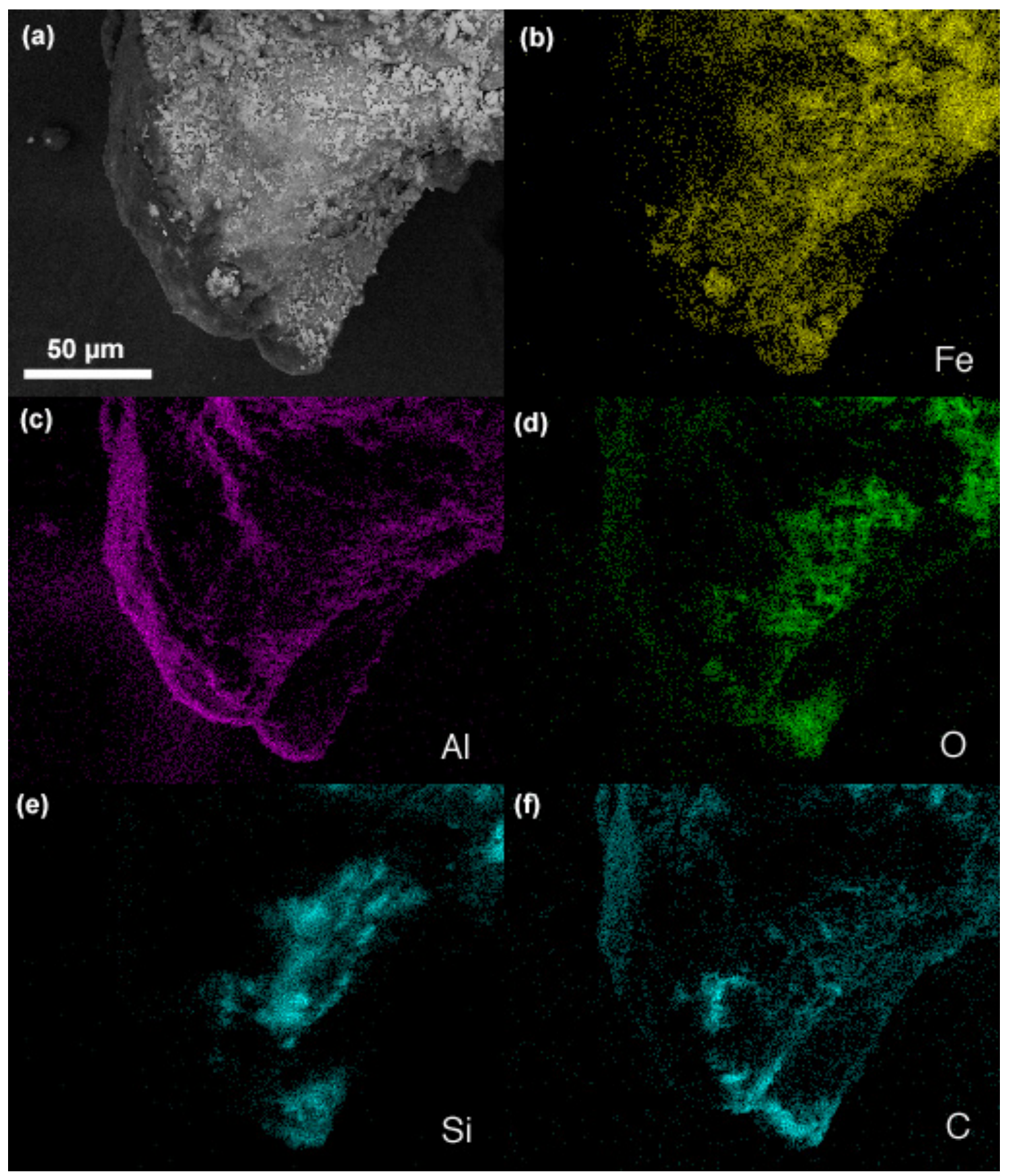

Fig. (15). (a) BSE image and (b)-(f) accompanying XEDS maps from the red layer of the chip which was soaked in methyl ethyl ketone for 55 hours. The maps for (b) $\mathrm{Fe},(\mathbf{c}) \mathrm{Al},(\mathbf{d}) \mathrm{O},(\mathbf{e}) \mathrm{Si}$, and (f) $\mathrm{C}$ are shown.

oxygen may not accompany it commensurately. To confirm and to quantify these observations, XEDS spectra (subsequent plots) were acquired from specific regions of high $\mathrm{Si}$, $\mathrm{Al}$ and $\mathrm{Fe}$ concentrations.

Focusing the electron beam on a region rich in silicon, located in Fig. (15e), we find silicon and oxygen and very little else (Fig. 16). Evidently the solvent has disrupted the matrix holding the various particles, allowing some migration and separation of the components. This is a significant result for it means that the aluminum and silicon are not bound chemically.
The next XEDS spectrum (Fig. 17) was acquired from a region that showed a high concentration of aluminum. Using a conventional quantification routine, it was found that the aluminum significantly exceeded the oxygen present (approximately a $3: 1$ ratio). Thus, while some of the aluminum may be oxidized, there is insufficient oxygen present to account for all of the aluminum; some of the aluminum must therefore exist in elemental form in the red material. This is an important result. Aluminum particles are covered with a layer of aluminum oxide irrespective of size, thus it is reasonable to find a significant oxygen content with the aluminum, given the very high surface area to volume ratio of these very fine particles. 


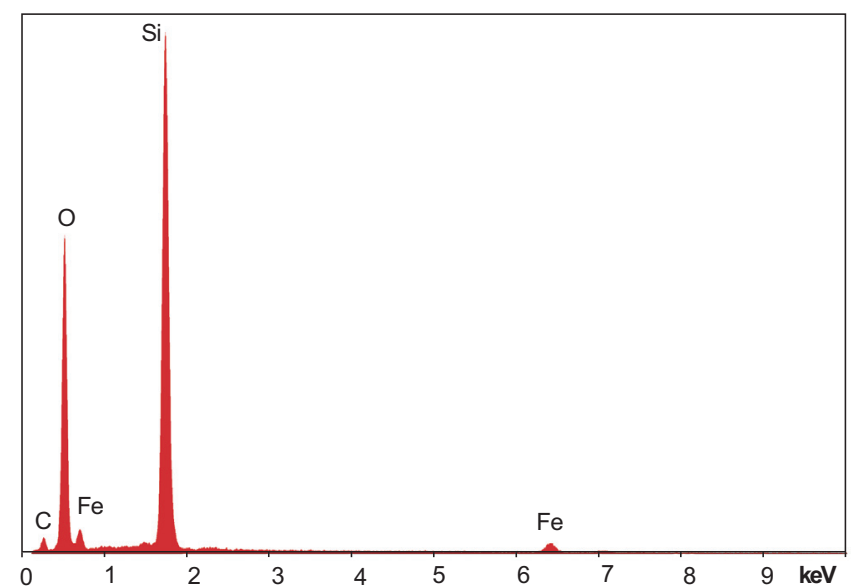

Fig. (16). XEDS spectrum from a silicon-rich region on the porous red matrix of the MEK-treated red material.

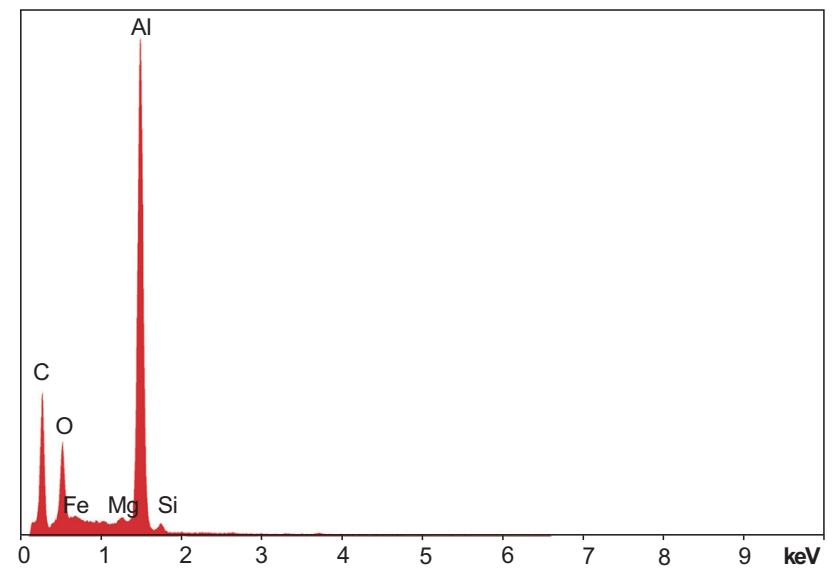

Fig. (17). XEDS spectrum obtained at $10 \mathrm{kV}$ from a probe of the region of high aluminum concentration on the MEK-soaked red chip.

Next a region of particularly high iron concentration was analyzed, yielding the XEDS spectrum shown in Fig. (18).

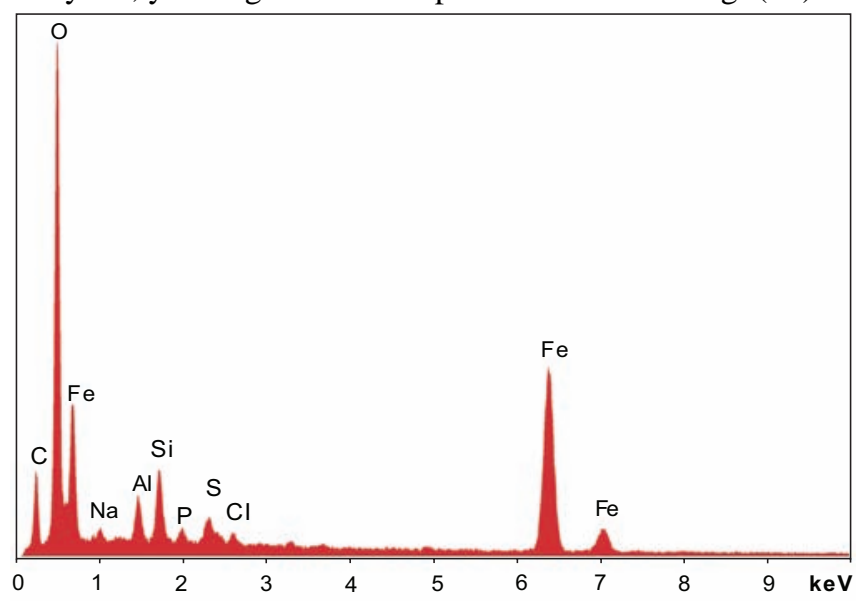

Fig. (18). XEDS spectrum obtained from a probe of the region of high iron concentration on the MEK-soaked red chip, acquired with a $15 \mathrm{kV}$ beam.

Oxygen is very consistently found in high concentration with the iron in the red material even after soaking in MEK solvent (Fig. 15), and in Fig. (18) an abundance of oxygen is found relative to iron. Based on quantification of the XEDS spectra, and after accounting for oxygen fractions to trace elements, it is found that the Fe:O ratio for the spectrum in Fig. (18) is approximately 2:3. This indicates that the iron is oxidized and apparently in oxidation state III, indicating that $\mathrm{Fe}_{2} \mathrm{O}_{3}$, or perhaps an iron (III) oxo-bridged polymer, is present.

To check the quantification method, tests were performed with the known chemical, iron (III) oxide, and the elementalquantification was found to yield consistent and repeatable results for iron and oxygen. In particular we made eight 50second measurements on $\mathrm{Fe}_{2} \mathrm{O}_{3}$ samples and found consistency for iron $( \pm 6.2 \%, 1$ sigma) and for oxygen $( \pm 3.4 \%, 1$ sigma) with the $\mathrm{O} / \mathrm{Fe}$ ratio consistently near 1.5 as expected.

The existence of elemental aluminum and iron oxide leads to the obvious hypothesis that the material may contain thermite. However, before concluding that the red material found in the WTC dust is thermitic, further testing would be required. For example, how does the material behave when heated in a sensitive calorimeter? If the material does not react vigorously it may be argued that although ingredients of thermite are present, the material may not really be thermitic.

\section{Thermal Analysis using Differential Scanning Calorimetry}

Red/gray chips were subjected to heating using a differential scanning calorimeter (DSC). The data shown in Fig. (19) demonstrate that the red/gray chips from different WTC samples all ignited in the range $415-435{ }^{\circ} \mathrm{C}$. The energy release for each exotherm can be estimated by integrating with respect to time under the narrow peak. Proceeding from the smallest to largest peaks, the yields are estimated to be approximately $1.5,3,6$ and $7.5 \mathrm{~kJ} / \mathrm{g}$ respectively. Variations in peak height as well as yield estimates are not surprising, since the mass used to determine the scale of the signal, shown in the DSC traces, included the mass of the gray layer. The gray layer was found to consist mostly of iron oxide so that it probably does not contribute to the exotherm, and yet this layer varies greatly in mass from chip to chip.

\section{Observation of Iron-Rich Sphere Formation Upon Ignition of Chips in a Differential Scanning Calorimeter}

In the post-DSC residue, charred-porous material and numerous microspheres and spheroids were observed. Many of these were analyzed, and it was found that some were iron-rich, which appear shiny and silvery in the optical microscope, and some were silicon-rich, which appear transparent or translucent when viewed with white light; see photographs taken using a Nikon microscope (Fig. 20).

The abundant iron-rich spheres are of particular interest in this study; none were observed in these particular chips prior to DSC-heating. Spheres rich in iron already demonstrate the occurrence of very high temperatures, well above the $700{ }^{\circ} \mathrm{C}$ temperature reached in the DSC, in view of the high melting point of iron and iron oxide [5]. Such high temperatures indicate that a chemical reaction occurred.

Using back-scattered electron (BSE) imaging, spheres were selected in the post-DSC residue which appeared to be rich in iron. An example is shown in Fig. (21) along with the corresponding XEDS spectrum for this sphere. 


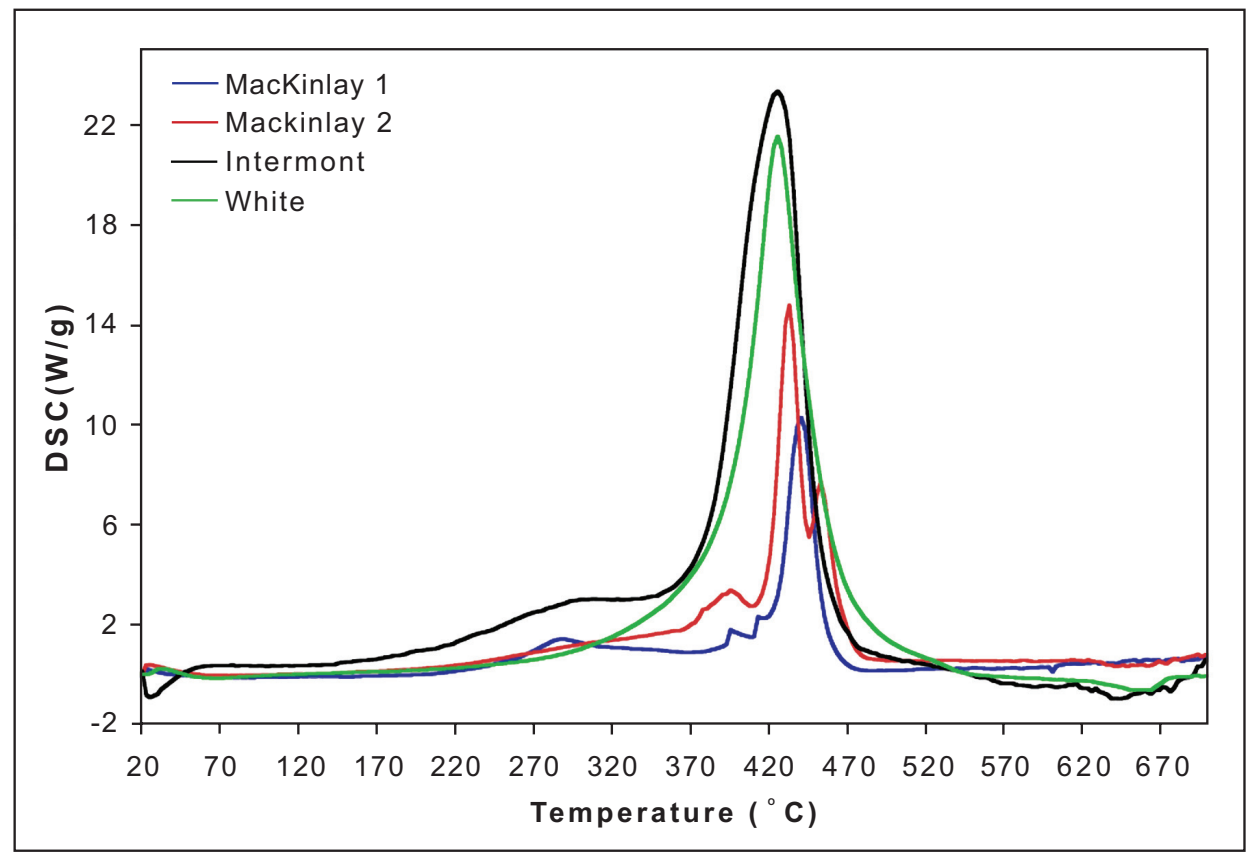

Fig. (19). Differential Scanning Calorimeter (DSC) traces for four red/gray chip samples found in World Trade Center dust collections.
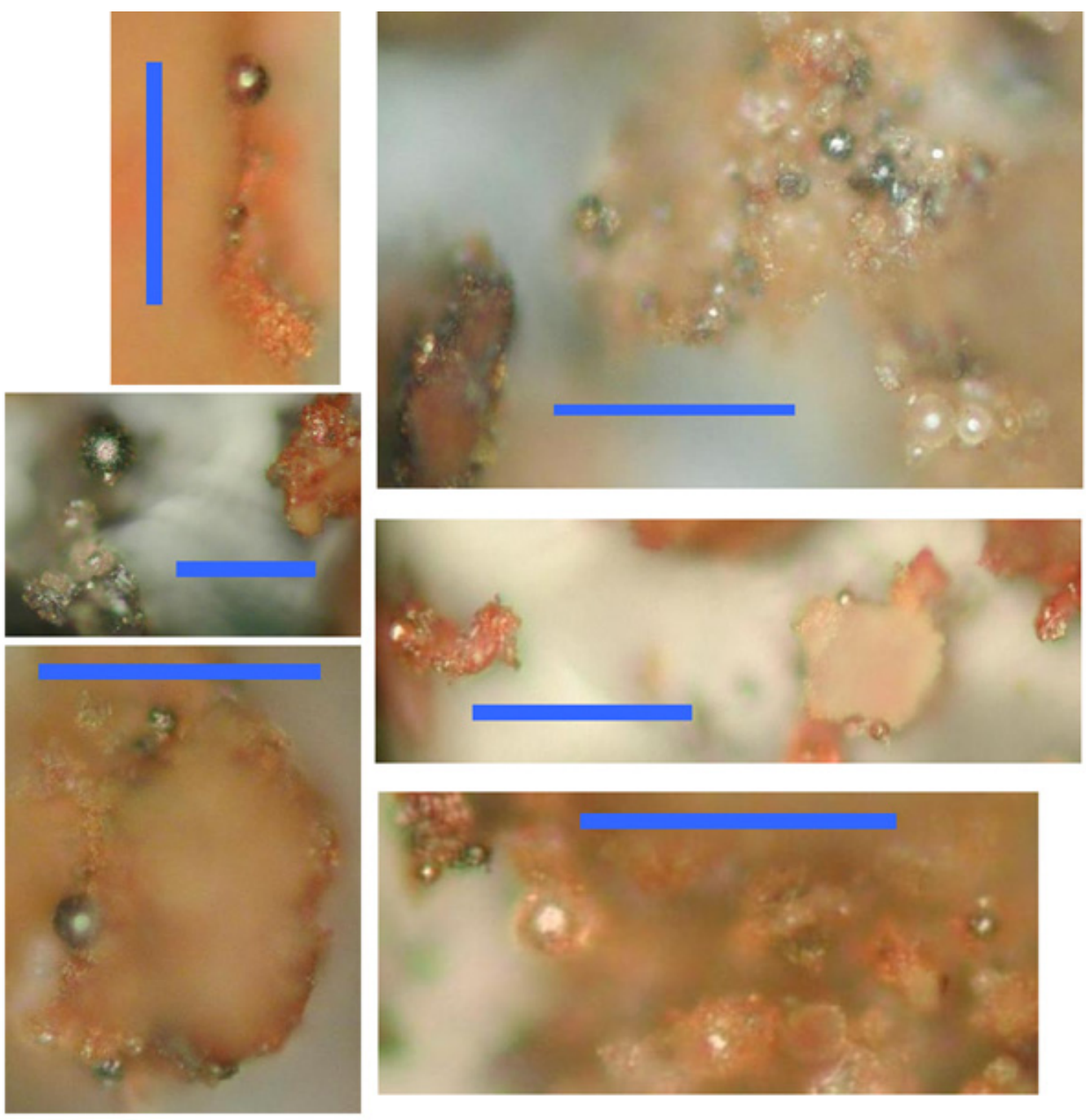

Fig. (20). Photomicrographs of residues from red/gray chips ignited in the DSC. Notice the shiny-metallic spheres and also the translucent spheres. Each blue scale-marker represents 50 microns. 

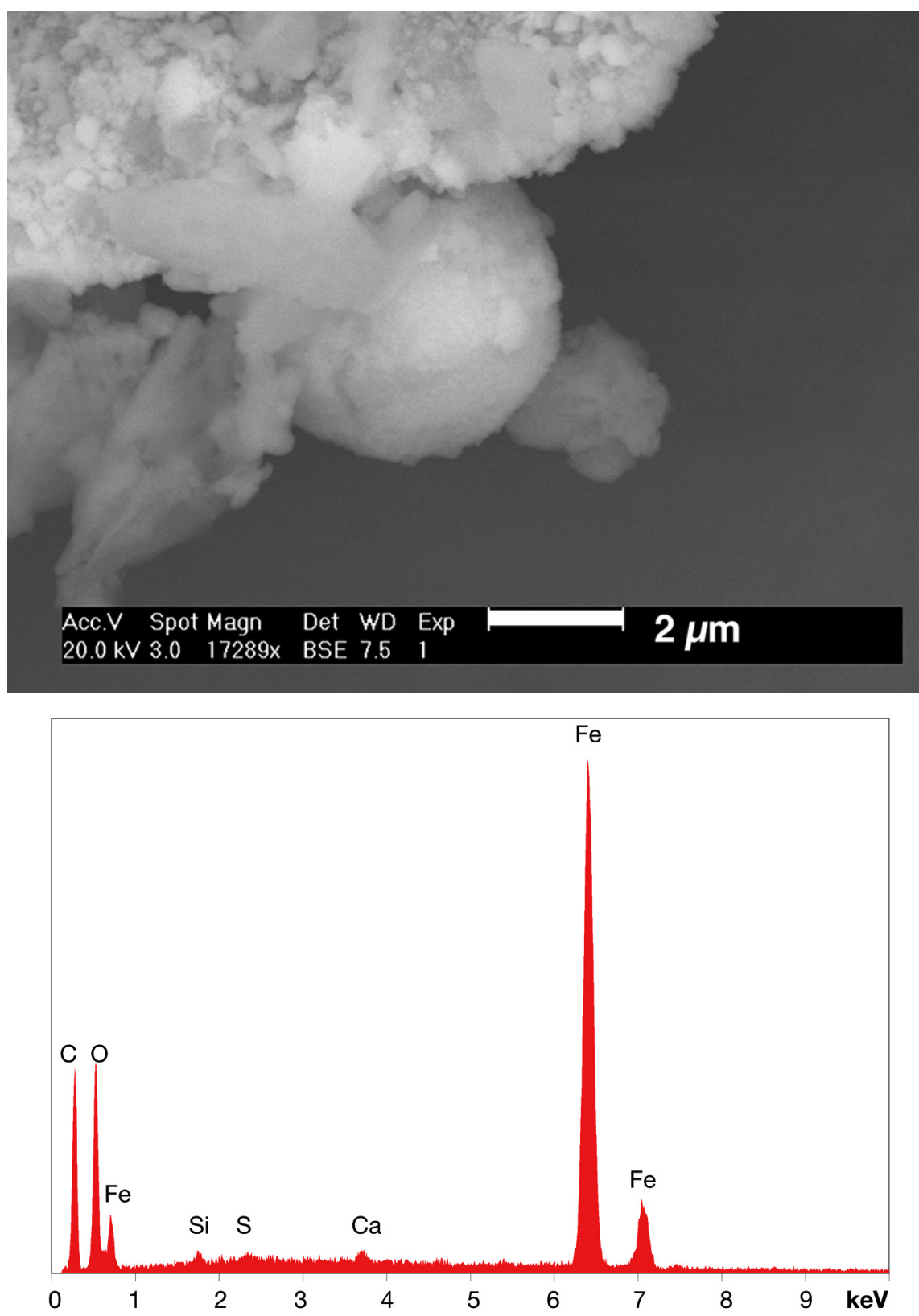

Fig. (21). Spheroid found in post-DSC residue showing iron-rich sphere and the corresponding XEDS spectrum. The carbon peak must be considered indeterminate here since this sample was flashed with a thin carbon layer in order to preclude charging under the electron beam.

A conventional quantitative analysis routine was used to estimate the elemental contents. In the case of this iron-rich spheroid, the iron content exceeds the oxygen content by approximately a factor of two, so substantial elemental iron must be present. This result was repeated in other iron-rich spheroids in the post-DSC sample as well as in spots in the residue which did not form into spheres. Spheroids were observed with $\mathrm{Fe}: \mathrm{O}$ ratios up to approximately $4: 1$. Other iron-rich spheres were found in the post-DSC residue which contained iron along with aluminum and oxygen (see Discussion section).

That thermitic reactions from the red/gray chips have indeed occurred in the DSC (rising temperature method of ignition) is confirmed by the combined observation of 1) highly energetic reactions occurring at approximately
$430{ }^{\circ} \mathrm{C}$, 2) iron-rich sphere formation so that the product must have been sufficiently hot to be molten (over $1400{ }^{\circ} \mathrm{C}$ for iron and iron oxide), 3) spheres, spheroids and nonspheroidal residues in which the iron content exceeds the oxygen content. Significant elemental iron is now present as expected from the thermitic reduction-oxidation reaction of aluminum and iron oxide.

The evidence for active, highly energetic thermitic material in the WTC dust is compelling.

\section{Flame/Ignition Tests}

The DSC used in our studies does not allow for visual inspection of the energetic reaction. Therefore tests were also performed with a small oxyacetylene flame applied to red/gray chips. Samples were either heated on a graphite block (Fig. 22) 

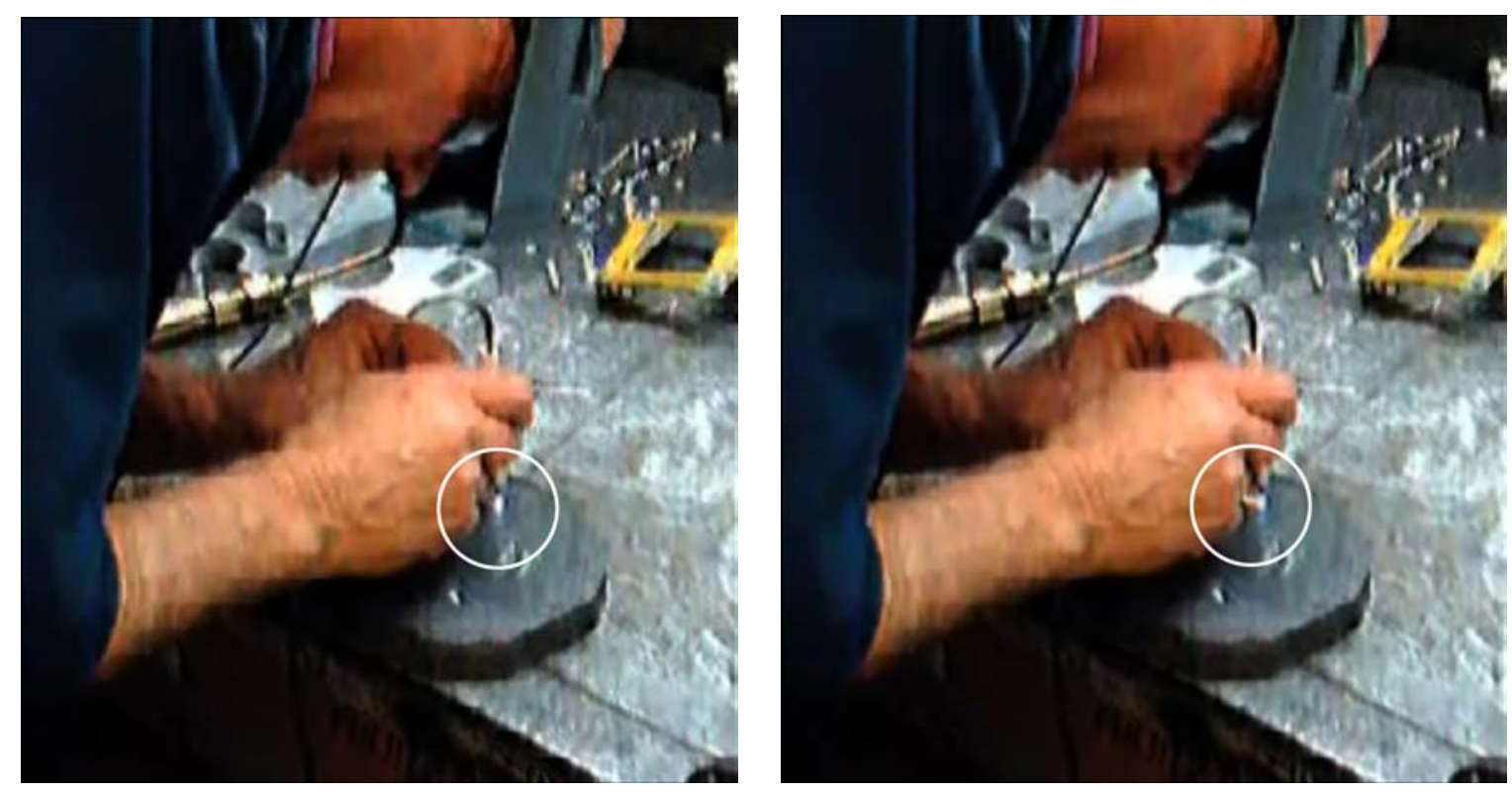

Fig. (22). Applying a small torch to a minute red chip (left), followed a few seconds later by ejection of material, producing a horizontal orange streak running toward the operator's hand (right). (Frames from video of this flame/ignition test).

or held with tweezers in the flame. Several paint samples were also tested and in each case, the paint sample was immediately reduced to fragile ashes by the hot flame. This was not the case, however, with any of the red/gray chips from the World Trade Center dust.

The first WTC red/gray chip so tested was approximately $1 \mathrm{~mm} \times 1 \mathrm{~mm}$. After a few seconds of heating, the high-speed ejection of a hot particle was observed under the hand of the person holding the torch (Fig. 22). The intense light and bright orange color of the particle attest to its high temperature. In this case, the attempt to recover the diminutive endproduct of the reaction was unsuccessful. A short video clip of the test (including slow-motion) is available here: http://journalof911studies.com/volume/2008/oxy_redchip_sl ow.mov

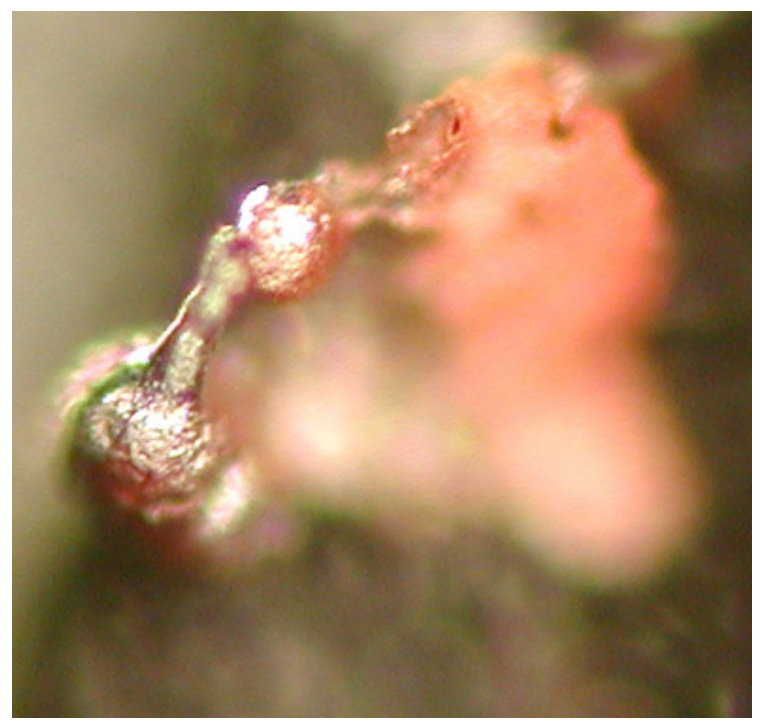

In a later flame-ignition test, the end product was recovered and is shown in the photomicrograph and SEM image in Fig. (23). Once again, the formation of iron-rich semispherical shapes shows that the residue had been melted, enabling surface tension of the liquid to pull it into spherical shapes. However, the evidence obtained in the DSC analyses is more compelling that a thermitic reaction actually occurs as in that case ignition is observed when the red material is heated to no more than $430{ }^{\circ} \mathrm{C}$.

\section{DISCUSSION}

All of the dust samples that were inspected were found to contain red/gray chips. The chips are characterized by a red layer in which XEDS analysis identifies carbon, oxygen, aluminum, silicon, and iron, and a gray layer in which mainly iron and oxygen are found. The ratios of these ele-

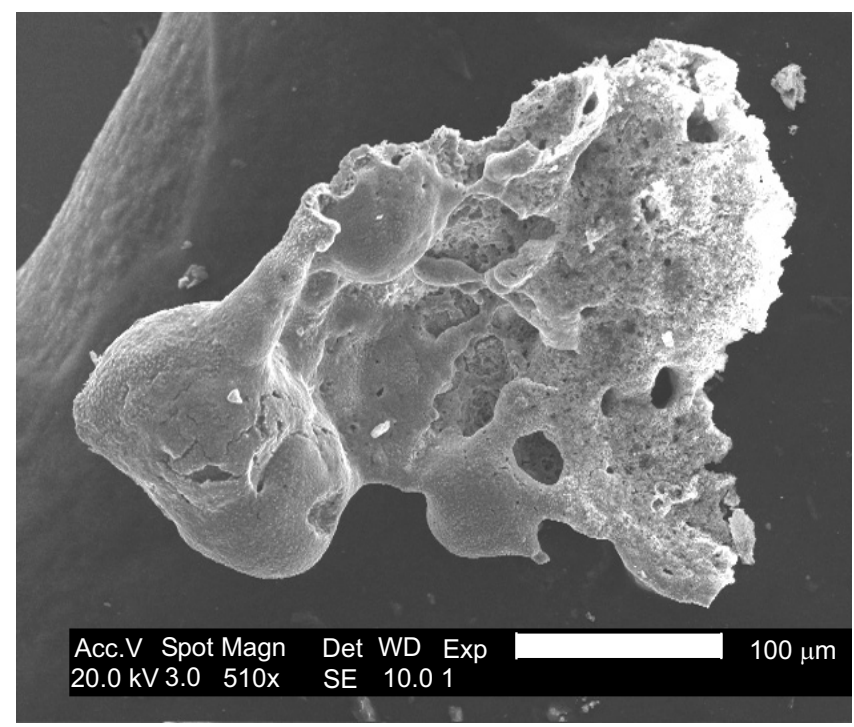

Fig. (23). Silvery-gray spheroids (left) are seen after the ignition test of red/gray chip from sample 1; some of the porous red material remains; both can be seen in the corresponding SEM image (right). 
ments appear to be similar especially when this analysis is performed on a clean cross-section of the layers. The BSE imaging also shows the consistency of the red layers by revealing the size and morphology of the particles that are contained in the bulk of the layers. The results clearly show the similarities of the red/gray chips from the different dust samples from all four sites.

There are a number of questions raised by our results.

\section{How Much of the Energetic Red Material Survived During the WTC Destruction?}

In the sample provided by collector J. MacKinlay the fraction of red/gray chips was roughly estimated. Fifteen small chips having a total mass of $1.74 \mathrm{mg}$ were extracted from a $1.6 \mathrm{~g}$ sample of dust from which readily identifiable glass and concrete fragments had been removed by hand. Thus the fraction of red/gray chips was approximately $0.1 \%$ by weight in the separated dust Another sampling showed 69 small red/gray chips in a 4.9 g sample of separated dust. Further samples are being analyzed to refine this estimate. The fall of the WTC Towers produced enormous clouds of dust whose total mass is difficult to ascertain; but clearly the total mass of red/gray chips in the WTC dust must be substantial given the fraction observed in these samplings.

\section{Is the Red Material Thermitic in Nature?}

Our observations show that the red material contains substantial amounts of aluminum, iron and oxygen, mixed together very finely. In the sample soaked in MEK, we observed a clear migration and aggregation of the aluminum away from other elements and determined that elemental aluminum and iron oxide must be present. In the product collected after DSC ignition, we found spheres which were not initially present. Many of these spheres were iron rich and elemental iron was found in the post-ignition debris. Further, the DSC traces demonstrate that the red/gray chips react vigorously at a temperature below the melting point of aluminum and below the ignition (oxidation) point of ultra- fine grain (UFG) aluminum in air [18]. These observations reminded us of nano-thermite fabricated at the Lawrence Livermore National Laboratory and elsewhere; available papers describe this material as an intimate mixture of UFG aluminum and iron oxide in nano-thermite composites to form pyrotechnics or explosives [19-21]. The thermite reaction involves aluminum and a metal oxide, as in this typical reaction with iron oxide:

$2 \mathrm{Al}+\mathrm{Fe}_{2} \mathrm{O}_{3} \rightarrow \mathrm{Al}_{2} \mathrm{O}_{3}+2 \mathrm{Fe}$ (molten iron), $\Delta \mathrm{H}=-853.5$ $\mathrm{kJ} / \mathrm{mole}$.

Commercially available thermite behaves as an incendiary when ignited [6], but when the ingredients are ultra-fine grain (UFG) and are intimately mixed, this "nano-thermite" reacts very rapidly, even explosively, and is sometimes referred to as "super-thermite" [20, 22].

We would like to make detailed comparisons of the red chips with known super-thermite composites, along with comparisons of the products following ignition, but there are many forms of this high-tech thermite, and this comparison must wait for a future study. Meanwhile, we compare with products of commercially available (macro-) thermite. During ignition of thermite, we have observed that many spheres and spheroids are formed as part of the molten product of the reaction is vigorously scattered. These particles tend to become spherical due to surface tension and, being small, are rapidly cooled and solidify as they fall through the air, thus their spherical shape is preserved.

To facilitate comparisons between the products of red/gray chip ignition and commercial thermite ignition, we juxtapose the respective images and XEDS spectra.

We observe that the spheroidal residues from ignition of red chips (Figs. 25, 26) possess a strikingly similar chemical signature to a typical XEDS spectrum from a spheroid generated by commercial thermite (Fig. 24). This similarity supports our hypothesis that the red chips are indeed a form of thermite.
Images of spheroids

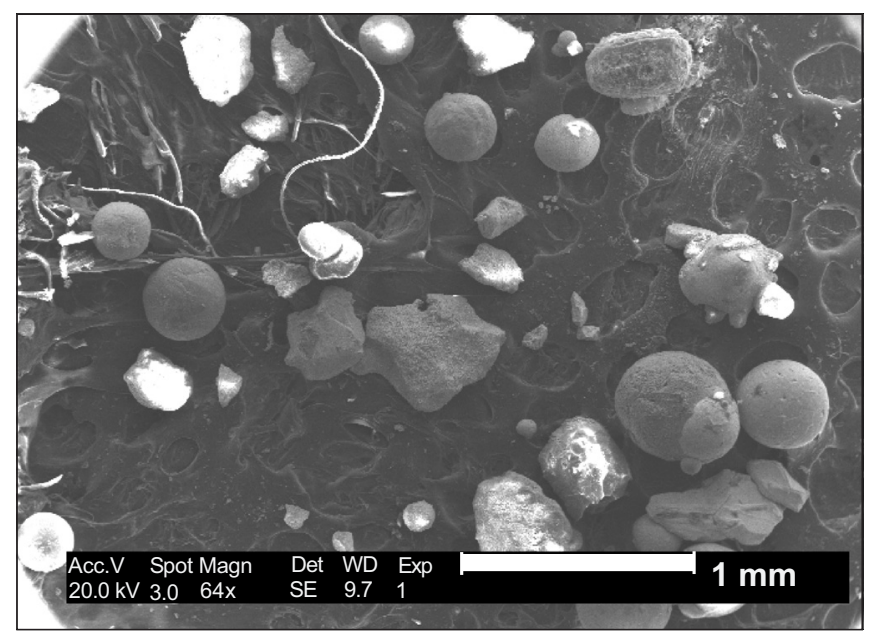

XEDS spectra of spheroids

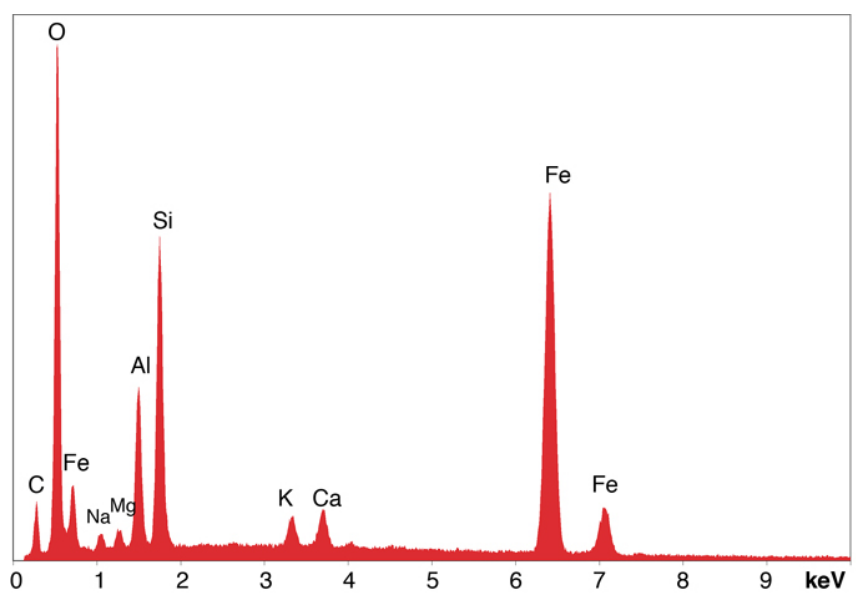

Fig. (24). Spheres formed during ignition of commercial thermite, with corresponding typical XEDS spectrum. 

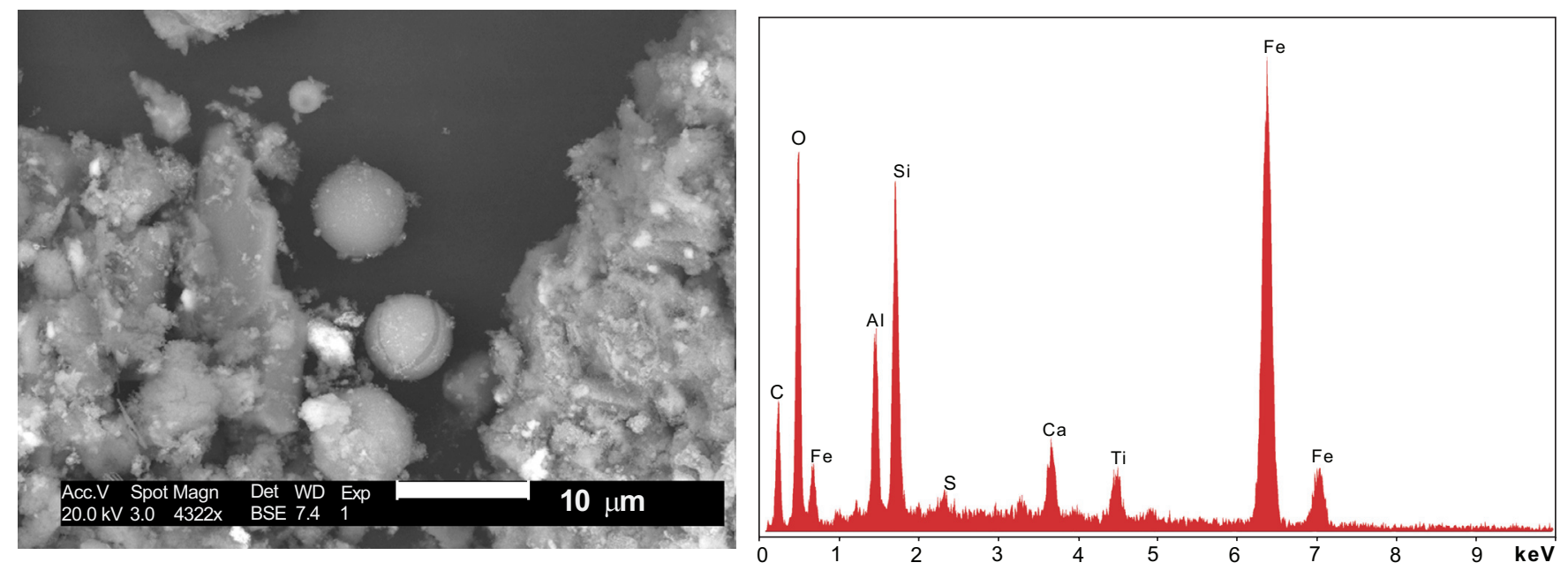

Fig. (25). Spheres formed during ignition of red/gray chip in DSC, with corresponding typical XEDS spectrum (although spheres with predominately iron and some oxygen are also seen in the post-ignition residue).
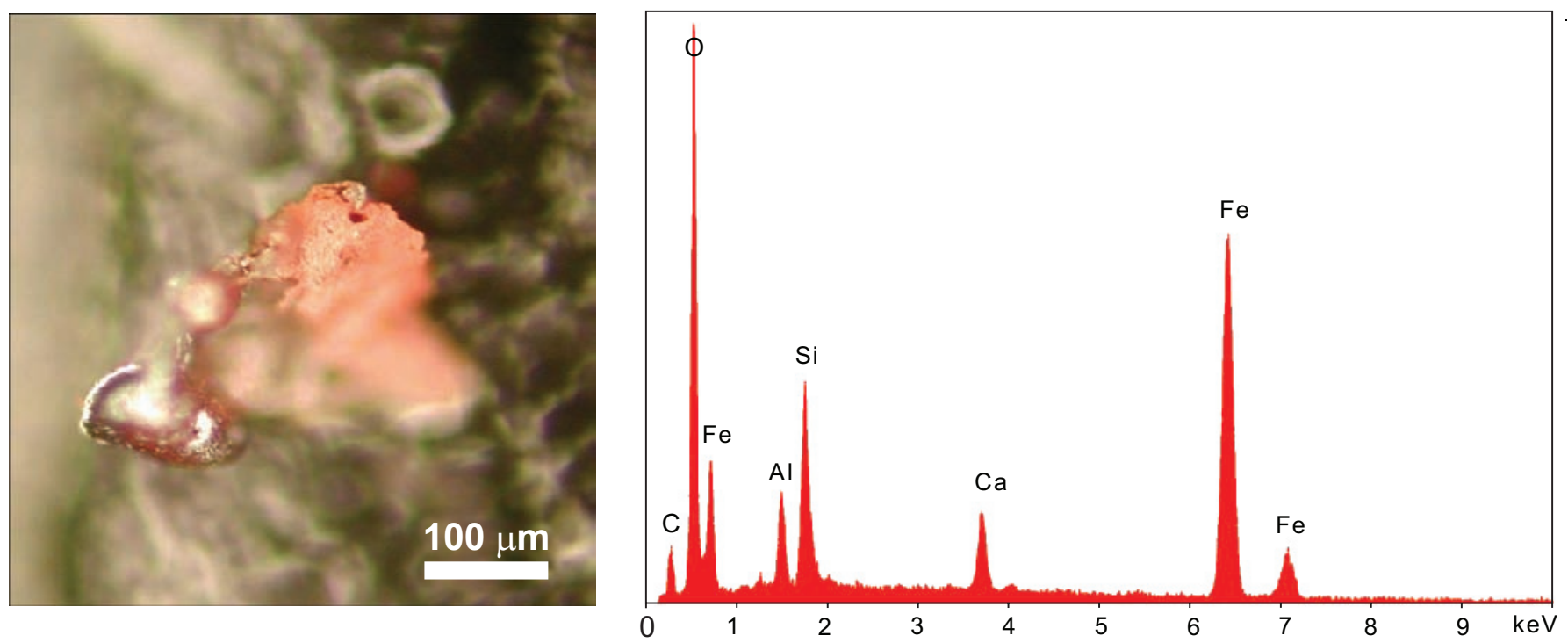

Fig. (26). Residue of red chip subjected to flame test; XEDS spectrum of left-most microsphere.
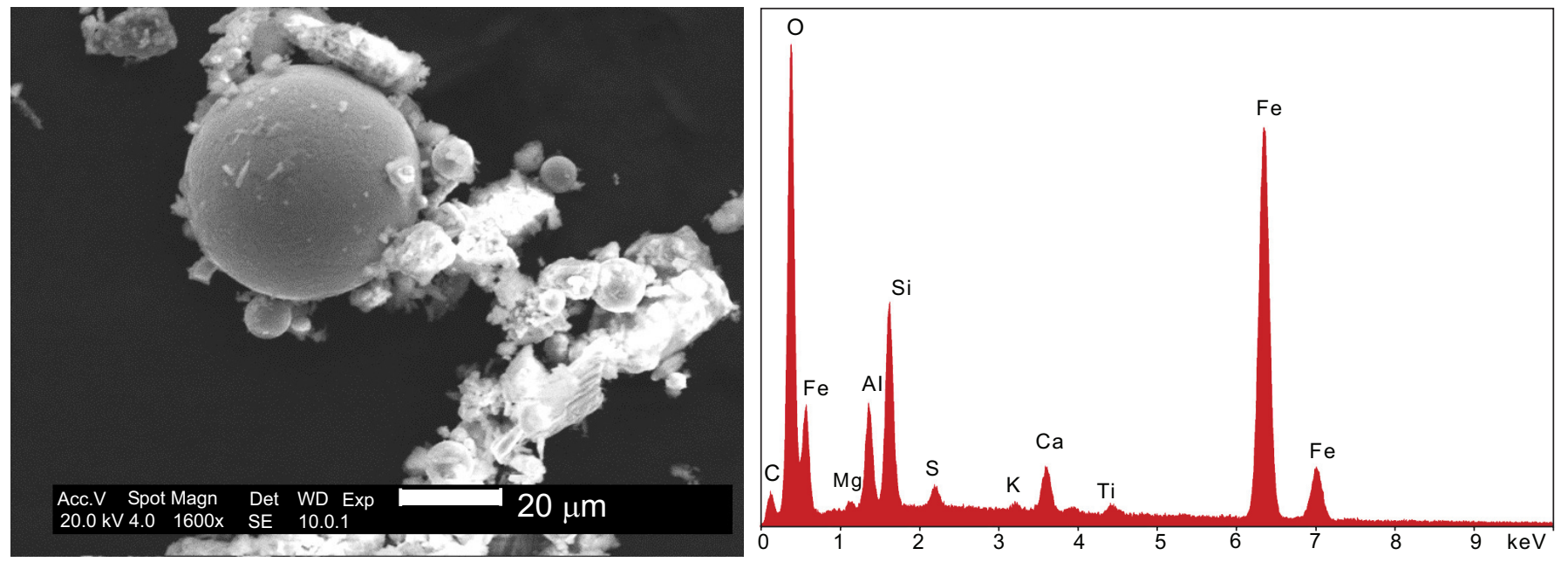

Fig. (27). Spheres extracted from WTC dust.

Fig. (28). XEDS spectrum from a sphere found in the WTC dust. 
In addition to the red/gray chips, many small spheres have been found by our group in the WTC dust. These contain the same elements as the residue of thermite, as noted in a previous paper [5]. We show spheres found in the WTC dust (Fig. 27) and a representative XEDS spectrum from such a sphere (Fig. 28); we invite the reader to compare these results with those found for ignition of commercial thermite and for ignition of red/gray chips (above).

\section{Could the Red Material Be Unreacted "Super- Thermite"?}

We have noted that ordinary thermite acts as an incendiary when ignited. However, when the ingredients are ultrafine-grain and are intimately mixed, the mixture reacts very rapidly, even explosively [20]. Thus, there is a highly energetic form of thermite known as an energetic nanocomposite or "super-thermite," composed of aluminum and iron oxide with at least one component being approximately $100 \mathrm{~nm}$ or less, often along with silicon and carbon [19-28].

\begin{abstract}
"Reaction rates between nanosize aluminum and metal oxides can be significantly greater than those observed with traditional micron-size thermite powders. Reactions occurring between metal and metal oxide powders are accompanied by the generation of high temperatures (>3000 K). Super-thermites, formed by mixing of aluminum and metal oxide nanopowders result in energy release rate by two orders of magnitude higher than similar mixtures consisting of micron size reactants" [22].
\end{abstract}

The red layer of the red/gray chips is most interesting in that it contains aluminum, iron and oxygen components which are intimately mixed at a scale of approximately 100 nanometers $(\mathrm{nm})$ or less. Now we compare a DSC trace obtained for a WTC red/gray chip with a DSC trace obtained for known super-thermite (see Fig. (29)).

Ordinary thermite ignites at a much higher temperature (about $900{ }^{\circ} \mathrm{C}$ or above) and gives a significantly broader trace than super-thermite [21]. All these data suggest that the thermitic material found in the WTC dust is a form of nanothermite, not ordinary (macro-) thermite. We make no attempt to specify the particular form of nano-thermite present until more is learned about the red material and especially about the nature of the organic material it contains.

\section{Did the Technology to Make Highly Exothermic Nano- composites Exist Prior to 9/11/2001?}

We find the answer in a report by Gash et al. dated April 2000 , seventeen months before the tragedy:

\begin{abstract}
"Nanostructured composites are multicomponent materials in which at least one of the component phases has one or more dimensions (length, width, or thickness) in the nanometer size range, defined as 1 to $100 \mathrm{~nm}$. Energetic nanocomposites are a class of material that have both a fuel and oxidizer component intimately mixed and where at least one of the component phases meets the size definition. A sol-gel derived pyrotechnic is an example of an energetic nanocomposite, in which metal-oxide nanoparticles react with metals or other fuels in very exothermic reactions. The fuel resides within the pores of the solid matrix while the oxidizer comprises at least a portion of the skeletal ma-
\end{abstract}

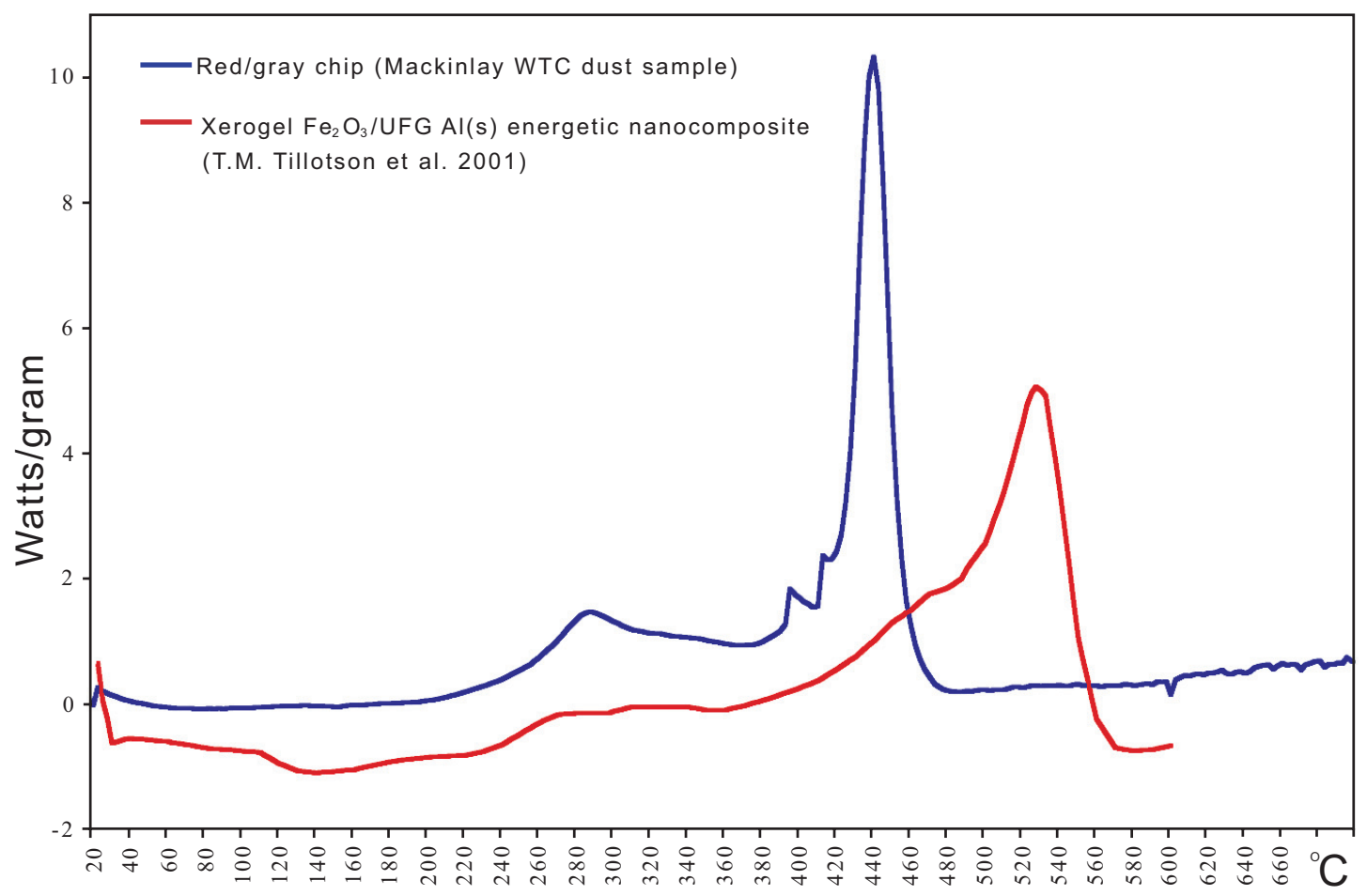

Fig. (29). DSC trace of sample 1 (blue line) compared with DSC of xerogel $\mathrm{Fe}_{2} \mathrm{O}_{3} / \mathrm{UFG}$ Al nanocomposite (from Tillotson et al. [28]). Both DSC traces show completion of reaction at temperatures below $560{ }^{\circ} \mathrm{C}$. 
trix." "As an example, energetic nanocomposites of $\mathrm{Fe}_{\mathrm{x}} \mathrm{O}_{\mathrm{y}}$ and metallic aluminum are easily synthesized. The compositions are stable, safe and can be readily ignited" [19].

We gather that the technology to make materials remarkably fitting the characterization of the red chips was available by April 2000. In the same report, the scientists noted that "polymers" can be added to the nanocomposite:

\begin{abstract}
"This sol-gel method allows for the addition of insoluble materials (e.g., metals or polymers) to the viscous sol, just before gelation, to produce a uniformly distributed and energetic nanocomposite upon gelation. Al metal (as a fine powder, $\sim 6 \mu \mathrm{m}$ diameter) was added to some $\mathrm{Fe}_{\mathrm{x}} \mathrm{O}_{\mathrm{y}}$ gel syntheses just before gelation to produce $\mathrm{Fe}_{\mathrm{x}} \mathrm{O}_{\mathrm{y}} / \mathrm{Al}(\mathrm{s})$ pyrotechnic nanocomposites.... These nanocomposites were subsequently processed to make both a xerogel and aerogel of the material.... The pyrotechnic nanocomposite can be ignited using a propane torch" [19].
\end{abstract}

Indeed, the red chips can be ignited using a torch and they have properties of a pyrotechnic nanocomposite. All the required ingredients are present - aluminum, iron, oxygen, silicon, and carbon - and they are incorporated in such a way that the chip forms (and sometimes ejects) very hot material when ignited. The Gash report describes FTIR spectra which characterize this energetic material. We have performed these same tests and will report the results elsewhere. We note that polymers in the matrix may be responsible for absorption of MEK and the subsequent swelling which we observed [29].

A report on an April 2001 conference discloses who was known to be working on such explosives at that time:

The 221st National Meeting of the American Chemical Society held during April 2001 in San Diego featured a symposium on Defense Applications of Nanomaterials. One of the 4 sessions was titled nanoenergetics.... This session provided a good representation of the breadth of work ongoing in this field, which is roughly 10 years old.... At this point in time, all of the military services and some DOE and academic laboratories have active $R \& D$ programs aimed at exploiting the unique properties of nanomaterials that have potential to be used in energetic formulations for advanced explosives.... nanoenergetics hold promise as useful ingredients for the thermobaric (TBX) and TBX-like weapons, particularly due to their high degree of tailorability with regards to energy release and impulse management [20].

The feature of "impulse management" may be significant. It is possible that formulations may be chosen to have just sufficient percussive effect to achieve the desired fragmentation while minimizing the noise level.

\section{Can Super-Thermite be Handled Safely?}

The April 2000 report by Gash et al. states:
"The nature of the wet nanocomposites also affords an additional degree of safety. In our hands, the wet pyrotechnic nanocomposites cannot be ignited until the drying process is complete. This property should allow the production of a large quantity of the pyrotechnics that can be stored safely for some time and dried shortly before its use" [19].

Safe handling of the malleable sol-gel material allows easy coating of surfaces (such as steel), which the same group, in a subsequent report, says they have achieved.

\begin{abstract}
"The sol-gel process is very amenable to dip-, spin-, and spray-coating technologies to coat surfaces. We have utilized this property to dipcoat various substrates to make sol-gel $\mathrm{Fe}_{2} \mathrm{O}_{3} / \mathrm{Al} /$ Viton coatings. The energetic coating dries to give a nice adherent film." "We have prepared fine powders, pressed pellets, cast monoliths, and thin films of the hybrid inorganic/organic energetic nanocomposite" [25].
\end{abstract}

Thus, the energetic nano-composite can be sprayed or even "painted" onto surfaces, effectively forming an energetic or even explosive paint. The red chips we found in the WTC dust conform to their description of "thin films" of "hybrid inorganic/organic energetic nanocomposite". Indeed, the descriptive terms "energetic coating" and "nice adherent film" fit very well with our observations of the red-chips which survived the WTC destruction. We cannot determine at this time, however, whether the thinness of the chips resulted from the application method or the manner of reaction. While the application of a thin film might have suited specific desired outcomes, it is also possible that the quenching effect of the steel the material was in contact with may have prevented a thin film of a larger mass from reacting. The fact that most of the chips have a distinctive gray layer suggests that the unreacted material was in close contact with something else, either its target, a container, or an adhesive.

Clapsaddle et al. further noted in their report:

"These results indicate that under ambient con-
ditions the hybrid inorganic/organic energetic
composite is very stable to impact, is spark in-
sensitive, and only very slightly friction sensi-
tive. As noted in the Experimental section of
this report, in our hands wet hybrid nanocompo-
sites are safe to handle and difficult to thermal
[sic] ignite. However, once dry the material
burns very vigorously and rapidly with the evo-
lution of significant amounts of gaseous spe-
cies" [24].

The organic component contributes to the rapid gas evolution and explosive nature of these energetic superthermites when dry [24].

"Super-thermite electric matches" have been developed at Los Alamos National Laboratory for which "applications include triggering explosives for ... demolition" [30]. It is indeed possible that such matches, which are designed to be ignited by a simple electric pulse, could contain material 
similar to the red material we have found in the WTC dust. With regard to the safety of super-thermite matches, the Los Alamos announcement notes:

\begin{abstract}
"Unfortunately, conventional electric matches use lead containing compounds that are extremely sensitive to impact, friction, static, and heat stimuli, thereby making them dangerous to handle. In addition, these compounds produce toxic smoke. The Super-Thermite electric matches produce no toxic lead smoke and are safer to use because they resist friction, impact, heat, and static discharge through the composition, thereby minimizing accidental ignition. They can be designed to create various thermal-initiating outputs - simple sparks, hot slag, droplets, or flames-depending on the needs of different applications" [30].
\end{abstract}

\section{What is the Energy Release of Super-Thermite Com- pared to Conventional Explosives?}

A graph in an article on nanostructured energetic materials [21] shows that the energy/volume yield for $\mathrm{Al} / \mathrm{Fe}_{2} \mathrm{O}_{3}$ composite material exceeds that of TNT, HMX and TATB explosives commonly used in demolitions (see Fig. (30)).

It is striking that some of the red/gray chips release more energy in $\mathrm{kJ} / \mathrm{g}$ than does ordinary thermite, as shown in the blue bar graphs above. The theoretical maximum for thermite is $3.9 \mathrm{~kJ} / \mathrm{g}$ [27]. We suggest that the organic material in evidence in the red/gray chips is also highly energetic, most likely producing gas to provide explosive pressure. Again, conventional thermite is regarded as an incendiary whereas super-thermite, which may include organic ingredients for rapid gas generation, is considered a pyrotechnic or explosive $[6,24]$. As this test was done in air it is possible that some of the enhancement of energy output may have come from air oxidation of the organic component.

\section{Could the Red Chip Material be Ordinary Paint?}

We measured the resistivity of the red material (with very little gray adhering to one side) using a Fluke 8842A multimeter in order to compare with ordinary paints, using the formula:

Specific resistivity $=R A / L$

where $R=$ resistance (ohms); $A=$ cross-sectional area $\left(\mathrm{m}^{2}\right) ; L$ $=$ thickness $(\mathrm{m})$.

Given the small size of the red chip, about $0.5 \mathrm{~mm} \times 0.5$ $\mathrm{mm}$, we used two probes and obtained a rough value of approximately $10 \mathrm{ohm}-\mathrm{m}$. This is several orders of magnitude less than paint coatings we found tabulated which are typically over $10^{10}$ ohm-m [31].

Another test, described above, involved subjection of red chips to methyl ethyl ketone solvent for tens of hours, with agitation. The red material did swell but did not dissolve, and a hard silicon-rich matrix remained after this procedure. On the other hand, paint samples in the same exposure to MEK solvent became limp and showed significant dissolution, as expected since MEK is a paint solvent.

Further, we have shown that the red material contains both elemental aluminum and iron oxide, the ingredients of thermite, in interesting configuration and intimate mixing in the surviving chips (see Results, section 1). The species are small (e.g., the iron oxide grains are roughly $100 \mathrm{~nm}$ across) in a matrix including silicon and carbon, suggesting a superthermite composite. Red chips when ignited produce very high temperatures even now, several years after the 9/11 tragedy, as shown by the bright flash observed and the pro-

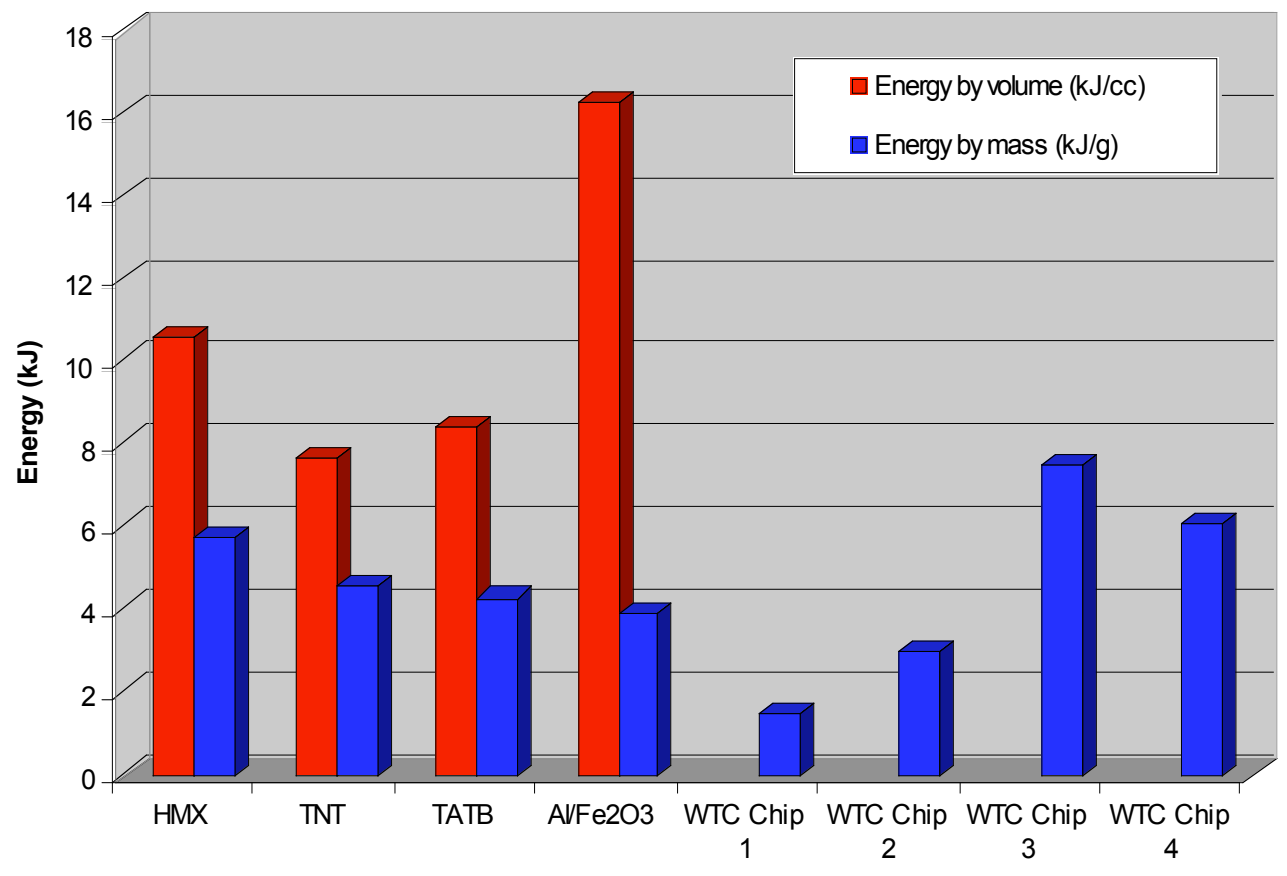

Fig. (30). Energy release for monomolecular explosives HMX, TNT and TATB, for energetic composite $\mathrm{Al} / \mathrm{Fe}_{2} \mathrm{O}_{3}$, [21] and energy release by mass for four red/gray chips found in the WTC dust as measured in a Differential Scanning Calorimeter. 
duction of molten iron-rich spheres (see photomicrographs in Fig. (20) above). Correspondingly, the DSC tests demonstrate the release of high enthalpy, actually exceeding that of pure thermite. Furthermore, the energy is released over a short period of time, shown by the narrowness of the peak in Fig. (29). The post-DSC-test residue contains microspheres in which the iron exceeds the oxygen content, implying that at least some of the iron oxide has been reduced in the reaction. If a paint were devised that incorporated these very energetic materials, it would be highly dangerous when dry and most unlikely to receive regulatory approval for building use. To merit consideration, any assertion that a prosaic substance such as paint could match the characteristics we have described would have to be accompanied by empirical demonstration using a sample of the proposed material, including SEM/XEDS and DSC analyses.

\section{What Future Studies are Contemplated?}

We observe that the total energy released from some of the red chips exceeds the theoretical limit for thermite alone $(3.9 \mathrm{~kJ} / \mathrm{g})$. One possibility is that the organic material in the red layer is itself energetic. Determination of the chemical compound(s) involved in the organic component of the red material would promote understanding. Further studies of the red material (separated from the gray material) compared to known super-thermite variants using DSC, TGA, FTIR (etc.) analyses would certainly be in order. In particular, NMR and GC-mass spectroscopy and related studies are urged to identify the organic material.

We have observed that some chips have additional elements such as potassium, lead, barium and copper. Are these significant, and why do such elements appear in some red chips and not others? An example is shown in Fig. (31) which shows significant $\mathrm{Pb}$ along with $\mathrm{C}, \mathrm{O}, \mathrm{Fe}$, and $\mathrm{Al}$ and displays multiple red and gray layers.

In addition, the gray-layer material demands further study. What is its purpose? Sometimes the gray material appears in multiple layers, as seen in Fig. (32).

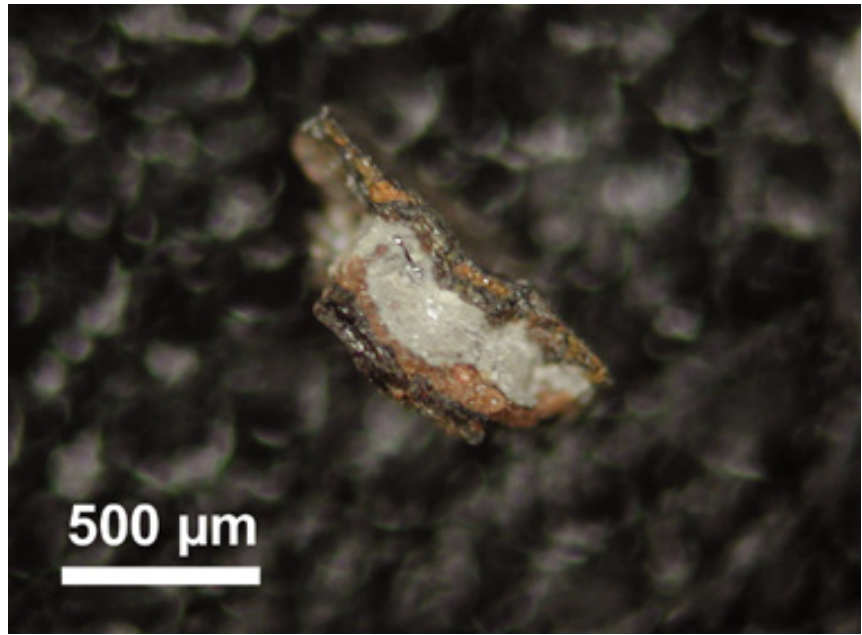

Fig. (31). Photomicrograph of a red/gray chip found in sample 3, showing multiple layers and an unusual light-gray layer between the red layers.

The red-mesoporous material is on the left in this view, with the touching dark-gray layer next and a lighter-gray material on the right as seen in a photograph of the same chip (right hand image in Fig. (32)). The gray layer in contact with the red layer has the XEDS spectrum shown in Fig. (33) in which iron is not seen, while the outer gray material had an XEDS spectrum just like those displayed in Fig. (6).

Thus, the middle-layer gray material contains carbon and oxygen and presumably also contains hydrogen, too light to be seen using this method. Since the gray inner layer appears between two other layers, it may be a type of adhesive, binding a red porous thermitic material to another, iron-rich material. One might speculate that the red thermitic material has been attached to rusty iron by an adhesive. The cooling effect of the iron in such close proximity, acting as a heat sink, might quench the reaction and explain the fact that unreacted red thermitic material, always found by us in thin layers, remains in the dust. These hypotheses invite further experiments.
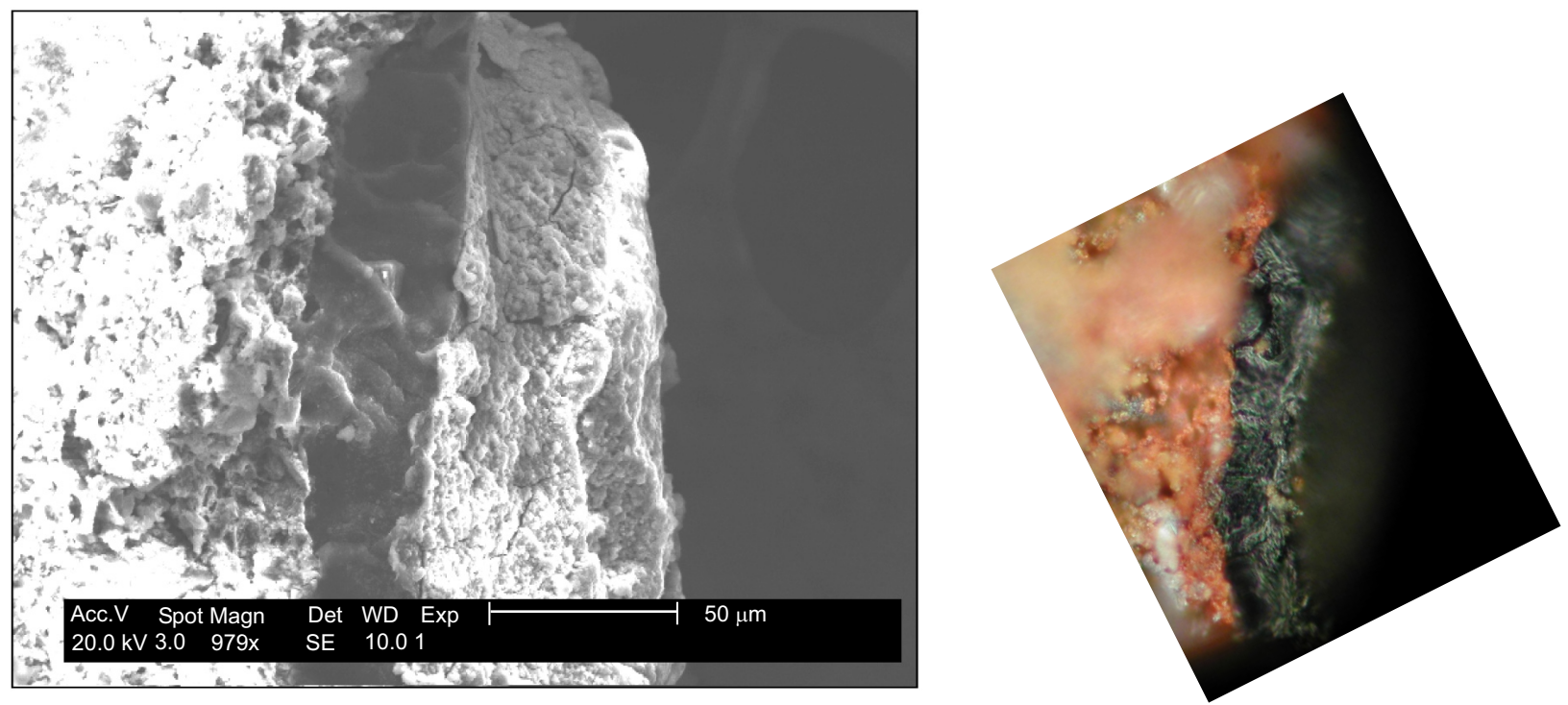

Fig. (32). Close-up SEM image of the chip pictured on the right, the same chip but not precisely the same spot. This chip had been treated in MEK solvent so that the red layer has expanded and porosity is evident. 


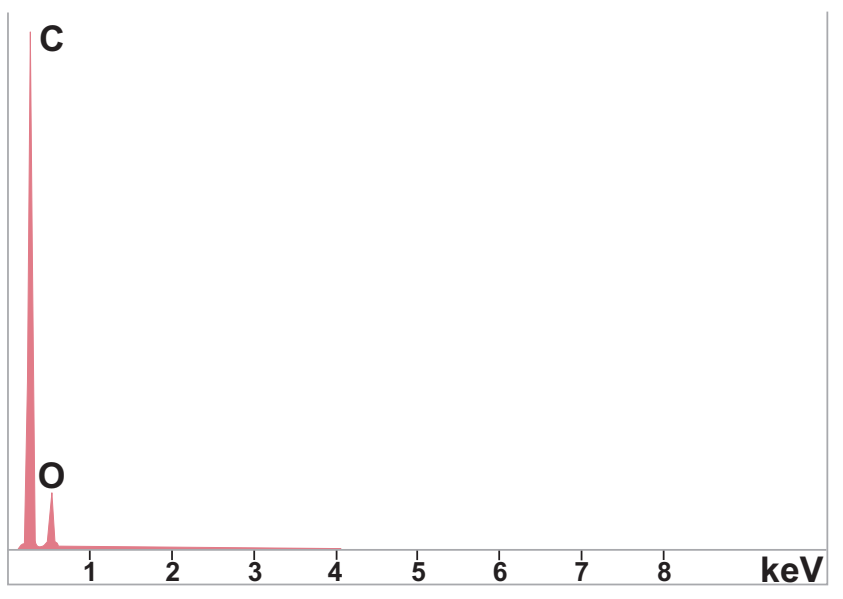

Fig. (33). XEDS spectrum for gray layer which touches the red layer of the chip shown above.

No red/gray chips having the characteristics delineated here were found in dust generated by controlled demolition using conventional explosives and methods, for the Stardust Resort \& Casino in Las Vegas (demolished 13 March 2007) and the Key Bank in Salt Lake City (demolished 18 August 2007). Of course, we do not assume that the destruction of the WTC skyscrapers occurred conventionally.

The red material does burn quickly as shown in the DSC, and we have observed a bright flash on ignition, but determination of the burn rate of the red material may help to classify this as a slow or fast explosive. It may be that this material is used not as a cutter-charge itself, but rather as a means to ignite high explosives, as in super-thermite matches [30]. Having observed unignited thermitic material in the WTC residue, we suggest that other energetic materials suitable for cutter charges or explosives should also be looked for in the WTC dust. NIST has admitted that they have not yet looked for such residues [11].

\section{CONCLUSIONS}

We have discovered distinctive red/gray chips in significant numbers in dust associated with the World Trade Center destruction. We have applied SEM/XEDS and other methods to characterize the small-scale structure and chemical signature of these chips, especially of their red component. The red material is most interesting and has the following characteristics:

1. It is composed of aluminum, iron, oxygen, silicon and carbon. Lesser amounts of other potentially reactive elements are sometimes present, such as potassium, sulfur, lead, barium and copper.

2. The primary elements (Al, Fe, O, Si, C) are typically all present in particles at the scale of tens to hundreds of nanometers, and detailed XEDS mapping shows intimate mixing.

3. On treatment with methyl ethyl ketone solvent, some segregation of components occurred. Elemental aluminum became sufficiently concentrated to be clearly identified in the pre-ignition material.
4. Iron oxide appears in faceted grains roughly $100 \mathrm{~nm}$ across whereas the aluminum appears in thin platelike structures. The small size of the iron oxide particles qualifies the material to be characterized as nanothermite or super-thermite.

5. Analysis shows that iron and oxygen are present in a ratio consistent with $\mathrm{Fe}_{2} \mathrm{O}_{3}$. The red material in all four WTC dust samples was similar in this way. Iron oxide was found in the pre-ignition material whereas elemental iron was not.

6. From the presence of elemental aluminum and iron oxide in the red material, we conclude that it contains the ingredients of thermite.

7. As measured using DSC, the material ignites and reacts vigorously at a temperature of approximately $430{ }^{\circ} \mathrm{C}$, with a rather narrow exotherm, matching fairly closely an independent observation on a known super-thermite sample. The low temperature of ignition and the presence of iron oxide grains less than $120 \mathrm{~nm}$ show that the material is not conventional thermite (which ignites at temperatures above $900{ }^{\circ} \mathrm{C}$ ) but very likely a form of super-thermite.

8. After igniting several red/gray chips in a DSC run to $700{ }^{\circ} \mathrm{C}$, we found numerous iron-rich spheres and spheroids in the residue, indicating that a very hightemperature reaction had occurred, since the iron-rich product clearly must have been molten to form these shapes. In several spheres, elemental iron was verified since the iron content significantly exceeded the oxygen content. We conclude that a high-temperature reduction-oxidation reaction has occurred in the heated chips, namely, the thermite reaction.

9. The spheroids produced by the DSC tests and by the flame test have an XEDS signature (Al, Fe, O, Si, C) which is depleted in carbon and aluminum relative to the original red material. This chemical signature strikingly matches the chemical signature of the spheroids produced by igniting commercial thermite, and also matches the signatures of many of the microspheres found in the WTC dust [5].

10. The carbon content of the red material indicates that an organic substance is present. This would be expected for super-thermite formulations in order to produce high gas pressures upon ignition and thus make them explosive. The nature of the organic material in these chips merits further exploration. We note that it is likely also an energetic material, in that the total energy release sometimes observed in DSC tests exceeds the theoretical maximum energy of the classic thermite reaction.

Based on these observations, we conclude that the red layer of the red/gray chips we have discovered in the WTC dust is active, unreacted thermitic material, incorporating nanotechnology, and is a highly energetic pyrotechnic or explosive material. 


\section{ACKNOWLEDGMENTS}

The authors wish to thank Tom Breidenbach, Frank Delessio, Jody Intermont, Janette MacKinlay, and Steve White for dust samples acquired soon after the WTC 9/11 catastrophe. We thank David Griscom, Mark Basile, David Allan, Branton Campbell, Wes Lifferth, Crockett Grabbe, David
Ray Griffin, Mike Berger, Frank Carmen, Richard Gage, Shane Geiger, Justin Keogh, Janice Matthews, John Parulis, Phillipe Rivera, Allan South and Jared Stocksmith for elucidating discussions and encouragement. Thanks to John Parulis for gathering samples of residues from reacted commercial thermite.

\section{REFERENCES}

[1] Federal Emergency Management Authority, World Trade Center Building Performance Study: Data collection, preliminary observations and recommendations, May 2002, Figure 1-7, Schematic depiction of areas of collapse debris impact, based on aerial photographs and documented damage, pp. 1-9. [Accessed February 7, 2009]. Available from partial mirrored version: http://911 research.wtc7.net/mirrors/guardian2/wtc/WTC ch1.htm

[2] Sunder S, Grosshandler W, Lew HS, et al. Final report on the collapse of the World Trade Center towers, NIST NCSTAR. National Institute of Standards and Technology: Gaithersburg, MD 2005.

[3] Gourley JR, McIlvaine B, Jones SE, Ryan K, Gage R. Appeal filed with NIST pursuant to earlier request for correction. J 9/11 Studies 2007; 17:1-16. [Accessed February 7, 2009]. Available from: http://www.journalof911studies.com/volume/2007/AppealLetterToNISTGourleyEtAl.pdf

[4] Ryan KR, Gourley JR, Jones SE. Environmental anomalies at the World Trade Center: evidence for energetic materials. Environmentalist 2009; 29(1): 56-63. [Accessed February 7, 2009]. Available from: http://www.springerlink.com/content/f67q6272583h86n4/

[5] Jones SE, Farrer J, Jenkins GS, et al. Extremely high temperatures during the World Trade Center destruction. J 9/11 Studies 2008; 19: 1-11. [Accessed February 7, 2009]. Available from: http:/www.journalof911studies.com/articles/WTCHighTemp2.pdf

[6] Jones SE. Why indeed did the WTC buildings completely collapse? J 9/11 Studies 2006; 3: 1-47. [Accessed February 7, 2009]. Available from: http://www.journalof911studies.com/volume/200609/WhyIndeedDidtheWorldTradeCenterBuildingsCompletelyCollapse.pdf

[7] Roberts G, Jones V. Robertson: a physicist and a structural engineer debate the controlled demolition of the World Trade Center. J 9/11 Studies 2007; 10: 1-37. [Accessed February 7, 2008]. Available from: http://journalof911studies.com/volume/200704/Roberts AnnotatedJonesRobertsonTranscript.pdf

[8] Jones SE. Revisiting 9/11 - applying the scientific method. J 9/11 Studies 2007; 11: 55-82. [Accessed February 7, 2009]. Available from: http://journalof911studies.com/volume/200704/JonesWTC911SciMethod.pdf

[9] Legge F, Szamboti T. 9/11 and the twin towers: sudden collapse initiation was impossible. J 9/11 Studies 2007; 18: 1-3. [Accessed February 7, 2009]. Available from: http://journalof911studies.com/volume/200703/Sudden collapse initiation impossible.pdf

[10] Gourley J. Discussion of 'mechanics of progressive collapse: learning from World Trade Center and building demolitions' by Bažant ZP, Mathieu V. J Eng Mech 2008; 134(10): 915-16. [Accessed February 7, 2009]. Available from:

http://scitation.aip.org/getabs/servlet/GetabsServlet?prog=normal\&id=JENMDT000134000010000915000001\&idtype=cvips\&gifs=yes

[11] Jones SE, Legge FM, Ryan KR, Szamboti AF, Gourley JR. Fourteen points of agreement with official government reports on the World Trade Center destruction. Open Civil Eng J 2008; 2: 35-40. [Accessed February 7, 2009]. Available from:

http://www.bentham-open.org/pages/content.php?TOCIEJ/2008/00000002/00000001/35TOCIEJ.SGM

[12] Hoffman J. The Demolition-Like symmetry of the Twin Towers' falls. [Accessed February 7, 2009]. Available from: http://911research.wtc7.net/wtc/analysis/collapses/symmetry.html

[13] McGee JK, Chen LC, Cohen MD, et al. Chemical analysis of world trade center fine particulate matter for use in toxicologic assessment. Environ Health Perspect 2003; 111: 972-80. [Accessed February 7, 2009]. Available from: http://www.ehponline.org/members/2003/5930/5930.html

[14] Lee RJ Group. WTC dust signature report, composition and morphology. December 2003. [Accessed February 7, 2009]. Available from: http://www.nyenvirolaw.org/WTC/130\%20Liberty\%20Street/Mike\%20Davis\%20LMDC\%20130\%20Liberty\%20Documents/Signature\%20of\%20WT C\%20dust/WTC\%20Dust\%20Signature.Composition\%20and\%20Morphology. Final.pdf

[15] Lowers HA, Meeker GP. Particle atlas of World Trade Center dust. September 2005; [Accessed February 7, 2009]. Available from: http://pubs.usgs.gov/of/2005/1165/508OF05-1165.html

[16] Lioy PJ, Weisel CP, Millette JR, et al. Characterization of the dust/smoke aerosol that settled east of the World Trade Center (WTC) in lower manhattan after the collapse of the WTC 11. September 2001. Environ Health Perspect 2002; 110(7): 703-14. [Accessed February 7, 2009]. Available from: http://www.ehponline.org/members/2002/110p703-714lioy/lioy-full.html

[17] Delessio F, Breidenbach T. Videotaped testimonies at Faneuil Hall, Boston, MA, December 2007. [Accessed February 7, 2009]. Available from: http://video.google.com/videoplay?docid=1957490867030316250, start at timestamp 34:54.

[18] Sun J, Pantoya ML, Simon SL. Dependence of size and size distribution on reactivity of aluminum nanoparticles in reactions with oxygen and MoO . $_{3}$ Thermochim Acta 2006; 444(2): 117-27. [Accessed February 7, 2009]. Available from: http://www.sciencedirect.com/science? ob=ArticleURL\& udi=B6THV-4JRVFRD$2 \&$ user $=10 \&$ rdoc $=1 \& \mathrm{fmt}=\&$ orig $=$ search $\&$ sort $=\mathrm{d} \&$ view $=\mathrm{c} \&$ acct $=\mathrm{C} 000050221 \&$ version $=1 \&$ urlVersion $=0 \&$ userid $=10 \& \mathrm{md} 5=\mathrm{cb} 52 \mathrm{f} 0 \mathrm{f} 9 \mathrm{dbc} 4$ aa13bc6fc39e223afa2f

[19] Gash AE, Simpson RL, Tillotson TM, Satcher JH, Hrubesh LW. Making nanostructured pyrotechnics in a beaker. pre-print UCRL-JC-137593, Lawrence Livermore National Laboratory: Livermore, Ca; April 10, 2000. [Accessed February 7, 2009]. Available from: http://www.osti.gov/energycitations/product.biblio.jsp?osti id=15007525

[20] Miziolek AW. Nanoenergetics: an emerging technology area of national importance. Amptiac Q 2002; 6(1): 43-48. [Accessed February 7, 2009]. Available from: http://www.p2pays.org/ref/34/33115.pdf

[21] Gash AE, Satcher JH, Simpson RL, Clapsaddle BJ. Nanostructured energetic materials with sol-gel methods. Mater Res Soc Symp Proc 2004; 800: 55-66. [Accessed February 7, 2009]. Available from: http://www.mrs.org/s mrs/sec subscribe.asp?CID=2642\&DID=115856\&action=detail

[22] Puszynski JA. Reactivity of nanosized Aluminum with metal oxides and water vapor. Mater Res Soc Symp Proc 2004; 800: AA6.4.1. [Accessed February 7, 2009]. Available from: http://www.mrs.org/s_mrs/sec_subscribe.asp?CID=2642\&DID=115976\&action=detail

[23] Puszynski JA, Swiatkiewicz JJ. Research Topic: Investigation of Ignition Characteristics of Heterogeneous Strongly Exothermic Reactions. Department of Chemical and Biological Engineering, South Dakota School of Mines and Technology, Current Projects. [Accessed February 7, 2009]. Available from: http://ret.sdsmt.edu/projectdescr.htm

[24] Clapsaddle BJ, Zhao L, Gash AE, et al. Synthesis and characterization of mixed metal oxide nanocomposite energetic materials. UCRL-PROC204118, Lawrence Livermore National Laboratory: Livermore, Ca; 12 May 2004. [Accessed February 7, 2009]. Available from: http://www.mrs.org/s mrs/sec subscribe.asp?CID=2642\&DID=115879\&action=detail

[25] Gash AE, Simpson RL, Satcher JH. Energetic nanocomposites with sol-gel chemistry: Synthesis, safety, and characterization. LLNL UCRL-JC146739, Lawrence Livermore National Laboratory: Livermore, Ca; 2002. [Accessed February 7, 2009 ]. Available from: http://e-reports-ext.llnl.gov/pdf/244137.pdf 
[26] Zhao L, Clapsaddle BJ, Satcher JH, Jr, Schaefer DW, Shea KJ. Integrated chemical systems: the simultaneous formation of hybrid nanocomposites of iron oxide and organo silsesquioxanes. Chem Mater 2005; 17(6): 1358-66.

[Accessed February 7, 2009]. Available from: http://pubs.acs.org/cgi-bin/abstract.cgi/cmatex/2005/17/i06/abs/cm048231i.html

[27] Clapsaddle BJ, Zhao L, Prentice D, et al. Formulation and performance of novel energetic nanocomposites and gas generators prepared by sol-gel methods. LLNL UCRL-PROC-210871, Lawrence Livermore National Laboratory: Livermore, Ca; March 2005;

[Accessed February 7, 2009]. Available from: http://e-reports-ext.llnl.gov/pdf/318263.pdf

[28] Tillotson TM, Gash AE, Simpson RL, Hrubesh LW, Satcher JH, Jr, Poco JF. Nanostructured energetic materials using sol-gel methodologies. J NonCryst Sol 2001; 285: 338-345. [Accessed February 7, 2009]. Available from: http://www.sciencedirect.com/science? ob=ArticleURL\& udi=B6TXM-435KKJV-

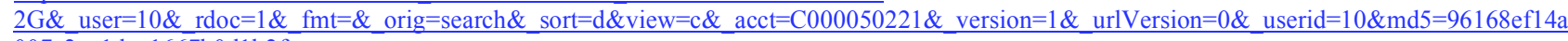
$007 \mathrm{c} 2 \mathrm{cc} 1 \mathrm{dee} 1667 \mathrm{~b} 0 \mathrm{~d} 1 \mathrm{~b} 2 \mathrm{f}$

[29] Bandyopadhyay A, de Sarkar M, Bhowmick AK. Polymer-filler interactions in sol-gel derived polymer/silica hybrid nanocomposites. J Polym Sci Part B. Polym Phys 2005; 43(17): 2399-412. [Accessed August 4, 2008]. Available from: http://www3.interscience.wiley.com/journal/110572549/abstract

[30] R\&D Awards. super-thermite electric matches. [Accessed February 7, 2009]. Available from: http://awards.lanl.gov/PDFfiles/Super-Thermite Electric Matches 2003.pdf

[31] Abu Ayana YM, El-Sawy SM, Salah SH. Zinc-ferrite pigment for corrosion protection. Anti-Corros Methods Mater 1997; 44(6): 381-8. Available from: http://www.emeraldinsight.com/Insight/ViewContentServlet?Filename=Published/EmeraldFullTextArticle/Articles/1280440604.html

(c) Harrit et al:; Licensee Bentham Open.

This is an open access article licensed under the terms of the Creative Commons Attribution Non-Commercial License (http: //creativecommons.org/licenses/by$\mathrm{nc} / 3.0 /$ ) which permits unrestricted, non-commercial use, distribution and reproduction in any medium, provided the work is properly cited. 